\title{
Propriedades mecânicas das argamassas estabilizadas: evolução com a idade e o grau de hidratação
}

\author{
Mechanical properties of ready mix mortar: evolution \\ with time and degree of hydration
}

\section{Juliana Machado Casali \\ Sabrina Mees \\ Alexandre Lima de Oliveira \\ Andrea MurilloBetioli \\ Luciana Maltez Calçada}

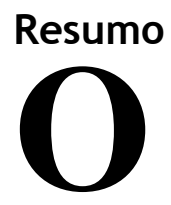

objetivo deste estudo foi avaliar as propriedades do estado fresco e endurecido e o grau de hidratação das argamassas estabilizadas ao longo do tempo. As argamassas foram produzidas com a mesma relação água/materiais secos (13\%) e teor de aditivo incorporador de ar ( $0,35 \%$ em relação à massa do cimento), com três teores de aditivo estabilizador de hidratação $(0 \%, 0,4 \%$ e $0,8 \%)$. As argamassas foram caracterizadas no estado fresco em dois tempos de utilização ( 0 hora e 48 horas) pela: consistência, densidade de massa, teor de ar incorporado, retenção de água, tempo de pega e parâmetros reológicos. As propriedades do estado endurecido foram avaliadas aos 7, 14, 28, 42 e 56 dias: resistência à compressão e tração; densidade da massa aparente e módulo de elasticidade dinâmico. Também foi avaliado o grau de hidratação por três métodos: perda ao fogo, análise termogravimétrica e difração de raios X. Os resultados obtidos demostraram influência do teor de aditivo estabilizador nas propriedades avaliadas. O grau de hidratação foi influenciado pelo teor de aditivo estabilizador e pelo tempo de utilização. Porém, não foi possível correlacionar grau de hidratação com a resistência à compressão, sendo esta influenciada também por outros fatores.

'Juliana Machado Casali Palavras-chave: Argamassa estabilizada. Grau de hidratação. Aditivo estabilizador de hidratação.

${ }^{2}$ Sabrina Mees ${ }^{2}$ Instituto Federal de Santa Catarina Florianópolis - SC - Brasil

${ }^{3}$ Alexandre Lima de Oliveira ${ }^{3}$ Instituto Federal de Santa Catarina Florianópolis - SC - Brasil

${ }^{4}$ Andrea Murillo Betioli ${ }^{4}$ Instituto Federal de Santa Catarina Florianópolis - SC - Brasil

${ }^{5}$ Luciana Maltez Calçada ${ }^{5}$ Instituto Federal de Santa Catarina Florianópolis - SC - Brasil

Recebido em 25/09/19

Aceito em 08/04/20

\section{Abstract}

The aim of the present study was to evaluate the properties of fresh and hardened state and the hydration degree of ready mix mortar at different ages. The mortars were produced with the same water/ dry materials ratio (13\%), same content of air-entrained admixtures (0.35\% of cement mass), while three contents of hydration stabilising admixtures $(0 \%, 0.4 \%$ and $0.8 \%)$ were evaluated. The ready mix mortars were characterised in two storage times ( 0 and 48 hours) in the fresh state through the consistency index, specific gravity, air entrained content, water retention, setting time and rheological parameters. In the hardened state, the mortars were evaluated at 7, 14, 28, 42 and 56 days for: compressive strength, tensile strength, specific gravity and elasticity modulus. The hydration degree was also evaluated by three methods: ignition loss, thermogravimetric analysis and $X$ ray diffraction. The results demonstrate that the content of hydration stabilising admixtureinfluencesthe properties of the mortars. The degree of hydration was influenced by the hydration stabilising admixture over time. However, it was not possible to correlate degree of hydration with compressive strength, which was influenced also by others factors.

Keywords: Ready mix mortar. Degree of hydration. Hydration stabilising admixtures.

CASALI, J. M.; MEES, S.; OLIVEIRA, A. L. de; BETIOLI, A. M.; CALÇADA, L. M. Propriedades mecânicas das argamassas 263 estabilizadas: evolução com a idade e o grau de hidratação. Ambiente Construído, Porto Alegre, v. 20 , n. 3, p. 263-283, jul./set. 2020. 


\section{Introdução}

Para aumentar a produtividade e racionalização das obras, uma das soluções é a utilização de argamassa estabilizada. Essa é uma argamassa industrializada úmida, cujos materiais constituintes, inclusive a água de amassamento, são pesados e misturados homogeneamente em uma central dosadora, fornecida pronta para sua aplicação no canteirodeobras e mantém sua trabalhabilidade por 36 a 72 horas. O aumento do tempo de trabalhabilidade da argamassa é obtido pela utilização de aditivos estabilizadores de hidratação, tendo a função de inibir a hidratação por um tempo pré-estipulado, que varia em função de teor utilizado.

O mecanismo de ação do aditivo estabilizador de hidratação está relacionado à inibição da nucleação do silicato de cálcio hidratado $(\mathrm{C}-\mathrm{S}-\mathrm{H})$ e do hidróxido de cálcio $\left(\mathrm{Ca}(\mathrm{OH})_{2}\right)$ ou portlandita, que atuam como agentes ativos de superfície, formando uma película hidrorrepelente ao redor das partículas de cimento (PAOLINI; KHURANA, 1998). Assim, esses aditivos aumentam o período de indução e alteram a taxa de hidratação dos compostos (CHEUNG et al., 2011).

A taxa de hidratação dos compostos ou a evolução das reações da hidratação do cimento Portland pode ser avaliada por vários métodos,segundo Neville (1997), tais como:

(a) quantidade de hidróxido de cálcio $\left(\mathrm{Ca}(\mathrm{OH})_{2}\right)$ na pasta;

(b) calor desenvolvido na hidratação;

(c) massa específica da pasta;

(d) quantidade de água quimicamente combinada;

(e) quantidade de cimento não hidratado presente; e

(f) indiretamente, pela resistência da pasta hidratada.

A medida da quantidade de água quimicamente combinada e da quantidade de hidróxido de cálcio ou portlandita obtidas da análise termogravimétrica (TG e DTG) é normalmente utilizada para acompanhar as reações de hidratação do cimento Portland ou a evolução de reação de materiais cimentícios complementares, como cinza volante (LOTHENBACH; DURDZINSKI; WEERDT, 2016). A quantidade de água obtida da desidratação do hidróxido de cálcio $\left(\mathrm{Ca}(\mathrm{OH})_{2}\right)$ ou portlandita pode ser determinada com análise termogravimétrica (TG e DTG) com a perda de água quimicamente combinada na faixa de temperaturas de $425^{\circ} \mathrm{C}$ a $550{ }^{\circ} \mathrm{C}$ (TAYLOR, 1997) ou $400{ }^{\circ} \mathrm{C}$ a $500{ }^{\circ} \mathrm{C}$ (LOTHENBACH; DURDZINSKI; WEERDT, 2016). Também com o objetivo de avaliar o grau de hidratação do cimento Portland, alguns trabalhos determinam a água não evaporável pelo ensaio de perda ao fogo avaliando-se a perda de massa em temperaturas de $900{ }^{\circ} \mathrm{C}$ a $1.000{ }^{\circ} \mathrm{C}$ (LAM; WONG; POON, 2000; NARMLUK; NAWA, 2011; MASUELA; CAMARINI, 2016) correlacionando com os outros parâmetros obtidos durante o ensaio, como, por exemplo, a perda de massa obtida pela desidratação do hidróxido de cálcio.

Nas argamassas, a influência do aditivo estabilizador de hidratação nas propriedades foi observada por Campos (2012) e Pivetta et al. (2016) com um aumento do tempo de início de pega com o aumento do teor de aditivo estabilizador. Além disso, o aditivo estabilizador, quando utilizado em quantidades excessivas, pode reduzir significativamente a resistência da argamassa para uma mesma idade (FIORAVANTE, 2014; BAUER; OLIVEIRA, 2017; ANTONIAZZI, 2019). Todavia, nos estudos realizados por Bauer e Oliveira (2017), o aditivo estabilizador de hidratação quando associado ao aditivo incorporador de ar, para uma mesma fluidez, reduziu o teor de água, contribuindo positivamente com as propriedades de resistência mecânica e absorção de água por capilaridade. Caso fosse mantida a quantidade de água, ocorreria uma diminuição na resistência à compreensão e na formação dos compostos hidratados, especialmente nas primeiras idades, conforme observado por Antoniazzi (2019).

Assim, este trabalho tem como objetivo avaliar as propriedades no estado fresco e endurecido e o grau de hidratação ao longo do tempo das argamassas estabilizadas comparando com uma argamassa referência sem aditivo estabilizador de hidratação.

\section{Materiais e métodos}

A seguir neste item serão descritos os materiais e métodos utilizados neste estudo.

264 Casali, J. M.; Mees, S.; Oliveira, A. L. de; Betioli, A. M.; Calçada, L. M. 


\section{Caracterização dos materiais utilizados}

Foi utilizado o cimento Portland composto com fíler (CP II - F - 32), atendendo à normalização brasileira, pois é o cimento Portland mais utilizado na região onde o trabalho foi desenvolvido (GUINDANI, 2018) e empregado em estudos anteriores como, por exemplo, Casali et al. (2011) e Antoniazzi (2019). As propriedades químicas e físicas estão apresentadas na Tabela 1. A distribuição granulométrica do cimento Portland obtida por granulometria a laser é apresentada na Figura 1a e a análise termogravimétrica do cimento Portland é apresentada na Figura 1b (onde foi observada um pico endotérmico obtido da descarbonização do $\mathrm{CaCO}_{3} 753,4^{\circ} \mathrm{C}$ com uma perda de massa de 4,32\%).

Tabela 1 - Características do cimento Portland utilizado

\begin{tabular}{|c|c|c|c|}
\hline \multicolumn{2}{|l|}{ Propriedades físicas } & \multicolumn{2}{|c|}{ Propriedades químicas* } \\
\hline Item de controle & Cimento & Item de controle & Cimento \\
\hline Porcentagem retida \#200 (\%) & 1,65 & $\mathrm{SiO}_{2}(\%)$ & 18,72 \\
\hline Porcentagem retida \#325 (\%) & 10,31 & $\mathrm{Al}_{2} \mathrm{O}_{3}(\%)$ & 3,89 \\
\hline Superfície específica - Blaine $\left(\mathrm{cm}^{2} / \mathrm{g}\right)$ & 3.268 & $\mathrm{Fe}_{2} \mathrm{O}_{3}(\%)$ & 2,63 \\
\hline Água de consistência normal (\%) & 26,7 & $\mathrm{CaO}(\%)$ & 60,88 \\
\hline Tempo de início de pega (horas) & 3:57 & $\mathrm{MgO}(\%)$ & 3,69 \\
\hline Tempo de final de pega (horas) & $4: 44$ & $\mathrm{~K}_{2} \mathrm{O}(\%)$ & 0,92 \\
\hline Expansibilidade a quente (mm) & 0,36 & $\mathrm{MnO}(\%)$ & $<0,05$ \\
\hline Resistência à compressão - 1 dia (MPa) & 16,2 & $\mathrm{Na}_{2} \mathrm{O}(\%)$ & 0,06 \\
\hline Resistência à compressão - 3 dias (MPa) & 30,4 & $\mathrm{P}_{2} \mathrm{O}_{5}(\%)$ & 0,12 \\
\hline Resistência à compressão - 7 dias (MPa) & 36,6 & $\mathrm{TiO}_{2}(\%)$ & 0,26 \\
\hline Resistência à compressão - 28 dias (MPa) & 43,3 & $\mathrm{SrO}(\%)$ & 0,25 \\
\hline Resíduo insolúvel (\%) & 1,14 & Perda ao fogo $(\%)$ & 5,31 \\
\hline Massa específica $\left(\mathrm{g} / \mathrm{cm}^{3}\right)$ & 3,06 & & \\
\hline
\end{tabular}

Fonte: resultados fornecidos pelo fabricante do cimento Portland.

Nota: *resultados obtidos pelos autores.

Figura 1 - (a) Distribuição granulométrica do cimento Portland e(b) perda de massa obtida pela análise termogravimétrica

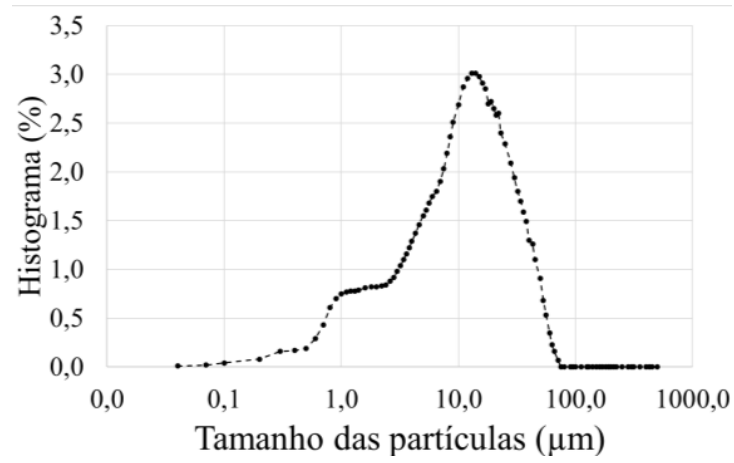

(a)

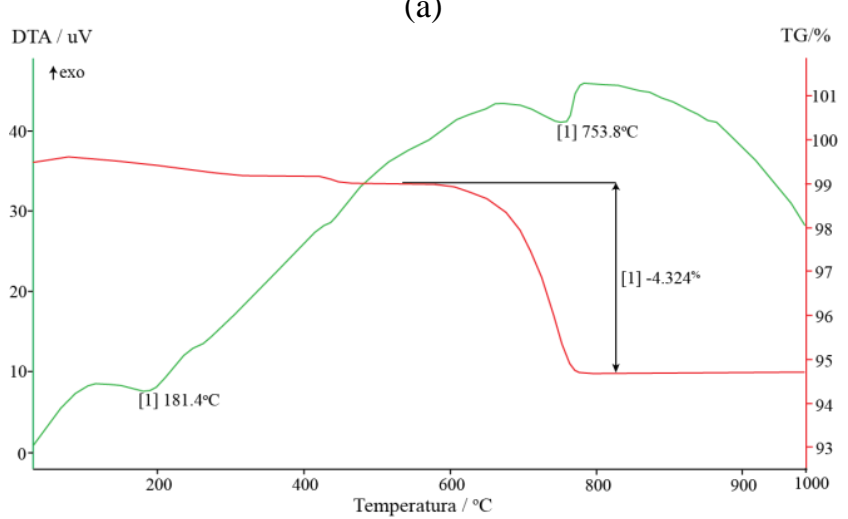

(b) 
O agregado miúdo utilizado foi uma areia natural proveniente de um fabricante de argamassa estabilizada da região da Grande Florianópolis. Na Tabela 2 são apresentadas a composição granulométrica (ABNT, 2003b), a massa específica aparente (ABNT, 2009) e o material pulverulento (ABNT, 2003a) do agregado miúdo empregado. A análise termogravimétrica é apresentada na Figura 3, indicando a presença de quartzo observada a $566,2{ }^{\circ} \mathrm{C}$, com uma perda de massa de $0,35 \%$.

Dois aditivos foram utilizados nas argamassas estabilizadas: um estabilizador de hidratação e um incorporador de ar (aditivos do mesmo fabricante e permitido o uso concomitante). As características dos aditivos são apresentadas na Tabela 3.

Tabela 2 - Propriedades físicas do agregado miúdo natural utilizado

\begin{tabular}{c|c}
\hline Abertura de peneira $(\mathbf{m m})$ & Porcentagem retida acumulada (\%) \\
\hline 4,8 & 0,0 \\
2,4 & 0,1 \\
1,2 & 2,2 \\
0,6 & 13,5 \\
0,3 & 44,7 \\
0,15 & 87,7 \\
Fundo & 100 \\
Dimensão máxima característica $(\mathrm{mm})$ & 1,2 \\
Dimensão mínima característica $(\mathrm{mm})$ & $<0,15$ \\
Módulo de finura & 1,48 \\
Massa específica aparente $\left(\mathrm{g} / \mathrm{cm}^{3}\right)$ & 2,64 \\
Material pulverulento $(\%)$ & 0,44 \\
\hline
\end{tabular}

Figura 2 - Perda de massa obtida pela análise termogravimétrica do agregado miúdo

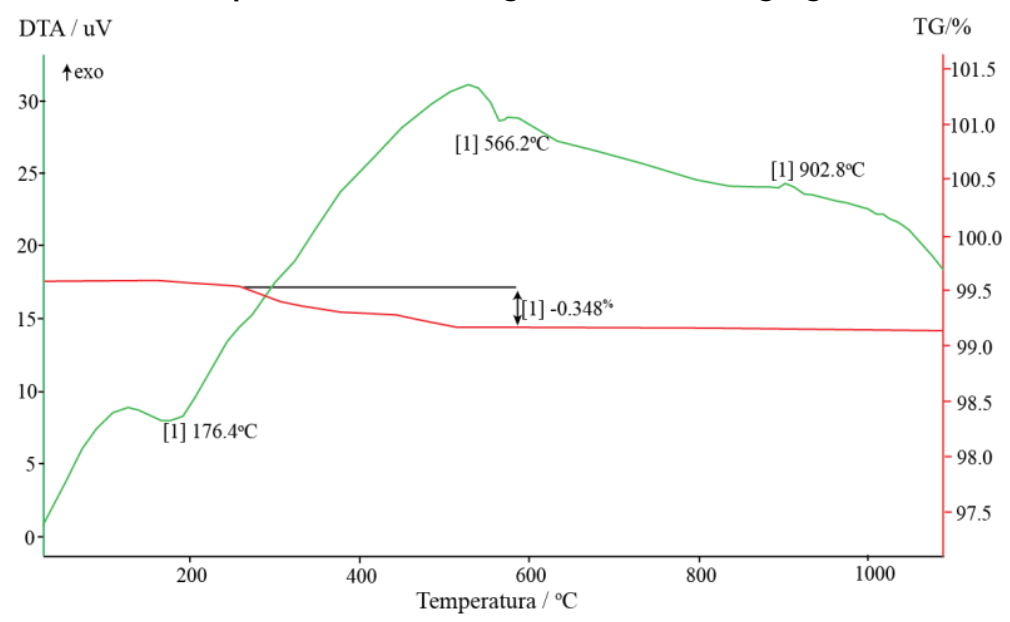

Tabela 3 - Característica dos aditivos químicos utilizados

\begin{tabular}{c|c|c}
\hline Aditivo & Aditivo estabilizador de hidratação & Aditivo incorporador de ar \\
\hline $\begin{array}{c}\text { Base química(Componente } \\
\text { de maior quantidade) }\end{array}$ & Não informado pelo fabricante & $\begin{array}{c}\text { Sal de álcool graxo etoxilado } \\
\text { sulfatado }\end{array}$ \\
\hline Teor de sólidos $(\%)$ & 45 & 3 \\
\hline Massa específica $\left(\mathrm{g} / \mathrm{cm}^{3}\right)$ & 1,17 & 1,00 \\
\hline $\mathrm{pH}\left(23^{\circ} \mathrm{C}\right)$ & 6 & 9 \\
\hline Estado físico & Líquido & Líquido \\
\hline Cor & Amarelado & Amarelo \\
\hline Dosagem recomendada & $\mathbf{0 , 2}$ a 1,5\% da massa do cimento & $\mathbf{0 , 1}$ a 0,5\% da massa do cimento \\
\hline
\end{tabular}

Fonte: resultados obtidos com o fabricante. 


\section{Produção e caracterização das argamassas estabilizadas}

A produção das argamassas estabilizadas foi realizada utilizando um traço 1:6 (cimento: areia), em massa e areia seca, pois é utilizado na região do estudo, sendo comprovado como traço médio em um levantamento realizado por Guindani (2018) em dez empresas que comercializam argamassa estabilizada nos três estados da Região Sul do Brasil. A quantidade de água utilizada foi fixada mantendo sempre a relação água/materiais secos de $13,0 \%$. Foram utilizados dois aditivos do mesmo fabricante usualmente utilizados nessas argamassas: um aditivo incorporador de ar, utilizado em todas as argamassas no teor de 0,35\% da massa do cimento em função dos resultados obtidos por Casali et al. (2018), e um aditivo estabilizador de hidratação para o qual se estabeleceu três teores para avaliação das argamassas: $0,0 \%$ (FR - referência), $0,4 \%$ (F4) e $0,8 \%$ (F8)em relação à massa de cimento. O teor de aditivo estabilizador de $0,8 \%$ foi escolhido em função do teor máximo utilizado pelos produtores da Grande Florianópolis e 0,4\% um teor intermediário. Foram avaliados dois tempos de armazenamento (0 hora e 48 horas) para as argamassas que continham o aditivo estabilizador.

As argamassas foram misturadas com emprego de uma argamassadeira de laboratório conforme NBR 7215 (2019) e preparadas em sala climatizada (temperatura de $23{ }^{\circ} \mathrm{C} \pm 3{ }^{\circ} \mathrm{C}$ ). O procedimento de mistura utilizado foi o descrito por Casali et al. (2018) e Mees et al. (2018). Esse procedimento foi realizado nove vezes e foram determinados para cada mistura a densidade de massa e o teor de ar incorporado (ABNT, 2005b) para verificação da similaridade entre cada mistura, sendo possível obter o coeficiente de variação dessas propriedades. Após a confecção das nove misturas, elas foram homogeneizadas em argamassadeira com capacidade de 40 litros com cuba móvel e pá fixa durante 5 minutos. Em seguida foram avaliadas as propriedades da argamassa no estado fresco (denominado tempo de utilização de 0 hora) e o restante do material foi armazenado em recipiente hermeticamente fechado até o tempo de utilização de 48 horas (para as argamassas com aditivo estabilizador) emsala climatizada (temperatura de $23{ }^{\circ} \mathrm{C} \pm 3{ }^{\circ} \mathrm{C}$ ). No tempo de utilização de 48 horas, antes de serem avaliadas as propriedades, a argamassa foi novamente homogeneizada na argamassadeira com capacidade de 40 litros, durante 5 minutos.

No estado fresco, para as argamassas avaliadas com 0 hora e 48 horas, determinou-se a densidade de massa e o teor de ar incorporado (de acordo com a NBR 13278 (ABNT, 2005b), a consistência (índice de consistência - flowtable - conforme a NBR 13276 (ABNT, 2016), a retenção de água (de acordo com a NBR 13277 (ABNT, 2005a) e o comportamento reológico utilizando o squeeze-flow (conforme a NBR 15839 (ABNT, 2010). Também foi determinado o tempo de início de pega em calorímetros semiadiabáticos (caixas de EPS revestidas com papel alumínio), onde foram verificadas as temperaturas usando termopar tipo $\mathrm{K}$ e a aquisição dos dados foi feita por meio de um data logger com leituras de $10 \mathrm{em} 10$ minutos. A partir dessas curvas, obteve-se o tempo de início de pega pelo método das derivadas (SANDBERG; LIBERMAN, $2007^{1}$ apud VIECILI; HASTENPFLUG; GIRARDI, 2018).

Para as argamassas com 48 horas, na data de avaliação foi determinada a relação água/materiais secos obtendo-se a quantidade de água da argamassa por secagem ao fogo.

Após a análise das propriedades no estado fresco, tanto com 0 hora quanto com 48 horas de utilização, foram moldados corpos de prova prismáticos (conforme a NBR 13279(ABNT, 2005c)) para avaliação das propriedades do estado endurecido nas idades de 7, 14, 28, 42 e 56 dias a partir da moldagem das amostras independentemente da idade de mistura da argamassa. No estado endurecido, as seguintes propriedades foram determinadas, em todas as idades, para os tempos de utilização de 0 e 48 horas: resistência à compressão (ABNT, 2005c); resistência à tração na flexão (ABNT, 2005c); densidade da massa aparente no estado endurecido (ABNT, 2005d) e módulo de elasticidade dinâmico (de acordo com a norma NBR 15630 (ABNT, 2008) com o auxílio de um aparelho de ultrassom da marca PUNDIT - LAB), sendo utilizado um coeficiente de Poisson de 0,2 .

A Figura 3 apresenta um organograma com o resumo do programa experimental.

\section{Avaliação do grau de hidratação das argamassas estabilizadas}

O grau de hidratação foi avaliado por três métodos: perda ao fogo, análise termogravimétrica e difração de raios X. Os três métodos serão descritos a seguir.

'SANDBERG, P.; LIBERMAN, S. Monitoring and evaluation of cement hydration by semiadiabaticfield calorimetry. In: WANG, K.; SCHINDLER, A; K. (ed.). Concrete heat development: monitoring, prediction, and management. New York: Curran Associates, 2007. 
Figura 3 - Organograma com o resumo do programa experimental

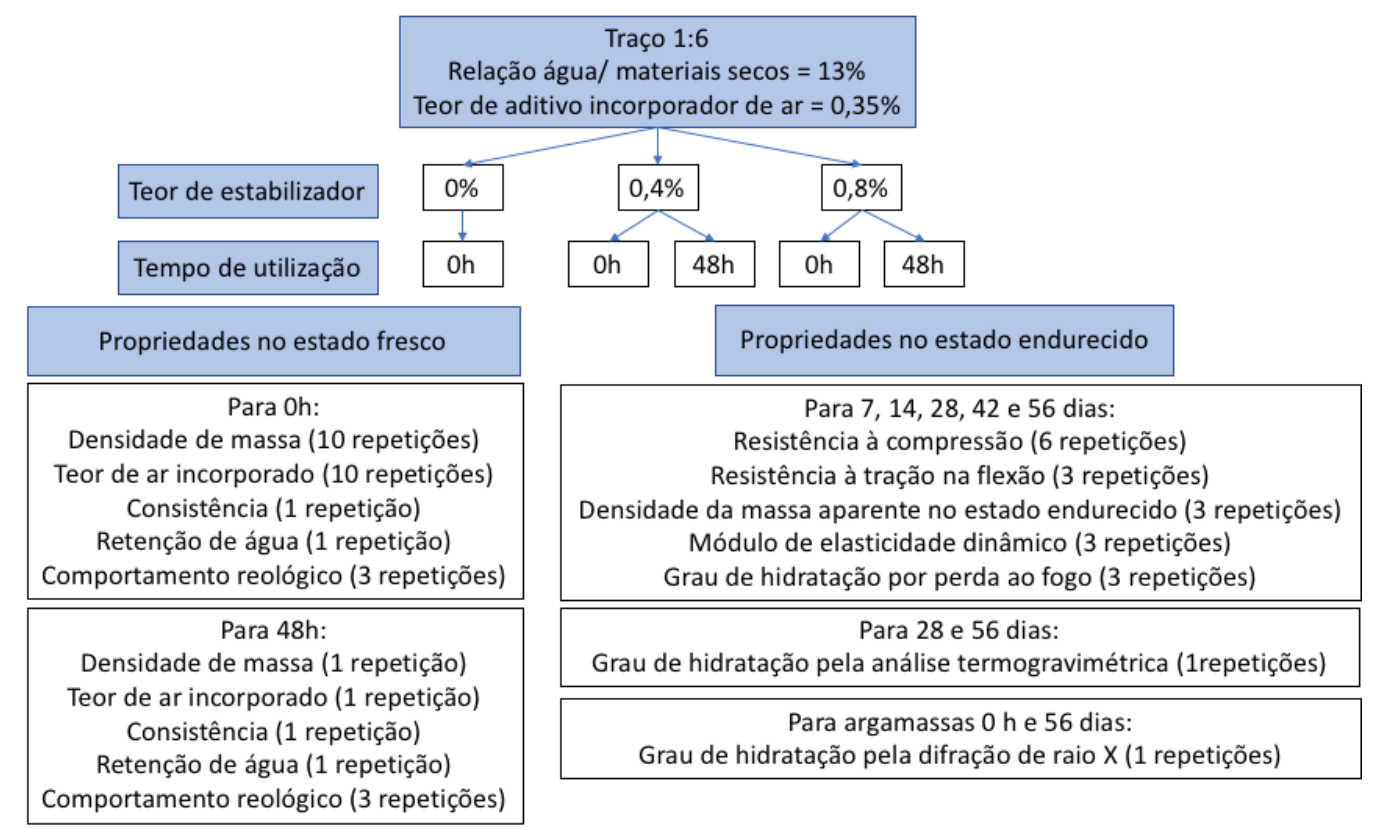

\section{Avaliação do grau de hidratação por perda ao fogo}

Na avaliação do grau de hidratação por perda ao fogo foram estabelecidas cinco idades para análise: 7, 14, 28, 42 e 56 dias. Nessas datas os corposdeprova rompidos foram triturados com um martelo e o resíduo peneirado em uma peneira de abertura de malha de 2,38mm, tomando-se a porção passante. Após o peneiramento, cerca de $30 \mathrm{~g}$ no total foram colocados em três cadinhos de porcelana e levados à estufa a $100^{\circ} \mathrm{C}$ por $24 \mathrm{~h}$ para determinação da perda da água livre. Em seguida foram colocados em um dessecador por 30 minutos para resfriamento e consequente pesagem.

Então, as amostras foram levadas para mufla onde permaneciam por uma hora na temperatura de $500{ }^{\circ} \mathrm{C}$, independentemente do tempo de elevação e de resfriamento do material. Ao término as amostras foram colocadas em um dessecador por 30 minutos para esfriar e após esse tempo eram pesadas. Após a pesagem, empregava-se o mesmo procedimento anterior, porém com a temperatura de $1.000{ }^{\circ} \mathrm{C}$. Esses procedimentos foram adaptados do utilizado por Masuela e Camarini (2016).

A partir dos valores obtidos foram calculados os seguintes parâmetros (adaptados de Gonçalvez, Toledo Filho e Fairbairn (2006)):

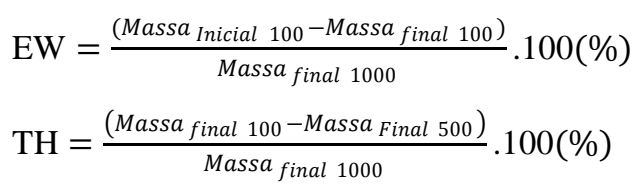

Onde:

EW: quantidade de água evaporável e dos primeiros compostos em relação à perda de massa de $1.000^{\circ} \mathrm{C}$;

Massa $_{\text {inicialioo: }}$ massa inicial referente à temperatura de $100^{\circ} \mathrm{C}$;

Massa $_{\text {finalloo: }}$ : massa final referente à temperatura de $100^{\circ} \mathrm{C}$;

Massa $_{\text {finallooo: }}$ : massa final referente à temperatura de $1.000{ }^{\circ} \mathrm{C}$;

TH: quantidade de água quimicamente combinada dos hidratos entre $100{ }^{\circ} \mathrm{C}$ e a temperatura final do pico característico ao hidróxido de cálcio em relação à perda de massa a $1.000{ }^{\circ} \mathrm{C}$; e

Massa $_{\text {finalsoo: }}$ massa final referente à temperatura de $500{ }^{\circ} \mathrm{C}$. 


\section{Avaliação do grau de hidratação pela análise termogravimétrica}

Para a análise térmica diferencial/termogravimétrica as amostras foram moídas em duas idades estipuladas de 28 e 56 dias em dois tempos de utilização (0 hora e 48 horas).Essas datas de ensaio foram estipuladas em função de um padrão de idade para materiais cimentícios ( 28 dias), inclusive para controle de qualidade, e uma idade avançada (56 dias) para verificar um possível aumento do grau de hidratação das argamassas com aditivo estabilizador de hidratação em função do retardo de pega/endurecimento inicial. Nessas datas os corpos de prova rompidos foram triturados com um martelo e o resíduo peneirado em uma peneira de abertura de malha de $2,38 \mathrm{~mm}$, tomando-se o material passante que foi enviado para laboratório para realização do ensaio com uma taxa de aquecimento de $10^{\circ} \mathrm{C} / \mathrm{min}$.

Com os dados obtidos da análise térmica, analisaram-se as perdas de massa em função da decomposição de compostos pré-estabelecidas pela bibliografia nas seguintes temperaturas:

(a) $20^{\circ} \mathrm{C}$ a $105^{\circ} \mathrm{C}$ : considerando a quantidade de água evaporável ou livre (LOTHENBACH, DURDZINSKI; WEERDT, 2016);

(b) $105^{\circ} \mathrm{C}$ a $400{ }^{\circ} \mathrm{C}$ : faixa de decomposição dos compostos hidratos (C-S-H, aluminatos e compostos de magnésio) (adaptado de Hoppe Filho(2008));

(c) $400{ }^{\circ} \mathrm{C}$ a $500{ }^{\circ} \mathrm{C}$ : faixa de desidratação do hidróxido de cálcio $\left(\mathrm{Ca}(\mathrm{OH})_{2}\right)$ ou portlandita (LOTHENBACH, DURDZINSKI; WEERDT, 2016); e

(d) $500{ }^{\circ} \mathrm{C}$ a $1.000{ }^{\circ} \mathrm{C}$ : faixa de decomposição do carbonato de cálcio e volatização do anidrido carbônico $\mathrm{CaCO}_{3}$ (adaptada de oppe Filho (2008)).

Para a determinação do teor de hidróxido de cálcio $\left(\mathrm{Ca}(\mathrm{OH})_{2}\right)$ ou portlandita e do teor do carbonato de cálcio $\left(\mathrm{CaCO}_{3}\right)$ foram utilizadas as equações 3 e 4, respectivamente, conforme apresentam Lothenback, Durdzinski e Weerdt (2016).

$\mathrm{Ca}(\mathrm{OH})_{2}=\frac{M_{\mathrm{Ca}(\mathrm{OH})_{2}}}{M_{\mathrm{H}_{2} \mathrm{O}}} \cdot \mathrm{H}_{2} \mathrm{O}=\frac{74}{18} \cdot \mathrm{H}_{2} \mathrm{O}=4,11 \cdot \mathrm{H}_{2} \mathrm{O}$

Onde:

$\mathrm{Ca}(\mathrm{OH})_{2}$ : de hidróxido de cálcio $\left(\mathrm{Ca}(\mathrm{OH})_{2}\right)$ ou portlandita;

$\mathrm{M}_{\mathrm{Ca}(\mathrm{OH})_{2}}$ : massa molecular de hidróxido de cálcio (74,09 mol);

$\mathrm{M}_{\mathrm{H}_{2} \mathrm{O}}$ : massa molecular da água (18,02 mol); e

$\mathrm{H}_{2} \mathrm{O}$ : perda de massa referente à decomposição de hidróxido de cálcio (\%).

$\mathrm{CaCO}_{3}=\frac{\mathrm{MaCO}_{3}}{\mathrm{M}_{\mathrm{CO}_{2}}} \cdot \mathrm{CO}_{2}=\frac{100}{44} \cdot \mathrm{PM}=2,27 \cdot \mathrm{CO}_{2}$

Onde:

$\mathrm{CaCO}_{3}$ : teor de carbonato de cálcio $\left(\mathrm{CaCO}_{3}\right)(\%)$;

$\mathrm{M}_{\mathrm{CaCO}_{3}}$ : massa molecular do carbonato de cálcio (100,09 mol);

$\mathrm{M}_{\mathrm{CO}_{2}}$ : massa molecular do anidrido carbônico (44,01 mol); e

$\mathrm{CO}_{2}$ : perda de massa referente à decomposição do anidrido carbônico (\%).

\section{Avaliação do grau de hidratação pela difração de raios $X$}

A difração de raios $\mathrm{X}$ foi determinada para as argamassas FR, F4 e F8 no tempo de utilização de 0 hora aos 56 dias, para comparação das argamassas e dos três métodos em uma fase mais avançada com teoricamente o maior grau de hidratação do cimento Portland. A amostra foi a mesma descrita anteriormente para análise termogravimétrica. O equipamento utilizado no ensaio foi um difratômetroBruker - D8 com goniômetro theta - theta. A radiação foi Ka em tubo de cobre nas condições de $40 \mathrm{kV}$ e $40 \mathrm{~mA}$. A velocidade e o intervalo de varredura do goniômetro foram de 1 grama de pó a 1 segundo para $0,02^{\circ}$ do goniômetro de $2^{\circ}$ a $72^{\circ} 2$ theta, respectivamente.

A quantificação das fases cristalinas identificadas na amostra foi realizada pelo Método de Rietveld, com $\mathrm{GOF}=1,63 \mathrm{e} \mathrm{Rwp}=14,44$. Os valores de quantificação são orientativos, devido à fase amorfa presente na amostra. Para a realização do ensaio com uma taxa de aquecimento de $10^{\circ} \mathrm{C} / \mathrm{min}$. 


\section{Resultados e discussões}

\section{Propriedades das argamassas estabilizadas}

$\mathrm{Na}$ Tabela 4 são apresentados os valores médios de índice de consistência, densidade de massa e teor de ar incorporado das argamassas estudadas. Além disso é apresentado o coeficiente de variação para a densidade de massa e do teor de ar incorporado.

Com relação aos valores de índice de consistência na Tabela 4, observa-se que, para o tempo de utilização de 0 hora, houve uma diferença pequena $(2 \mathrm{~mm})$ entre o valor obtido para a argamassa de referência e para as argamassas com aditivo estabilizador. As argamassas com tempo de utilização de 48 horas apresentaram redução de consistência em relação às de mesmo teor de aditivo no tempo de 0 hora, bem como em relação à argamassa de referência.

Os valores de teor de ar incorporado diminuíram com a utilização e o aumento do teor de aditivo estabilizador. Para as argamassas de 0 hora, verificou-se uma diferença significativa nos teores de ar incorporado (Tabela 4) (com 95\% de nível de confiança utilizando a comparação múltipla de médias na análise da variância pelo teste Duncan). Essa diferença só foi possível identificar, pois foram produzidas nove misturas e mais uma determinação após a homogeneização de todas elas. Pode-se observar o baixo coeficiente de variação obtido, demostrando uma boa reprodutibilidade e eficiência do processo de mistura utilizado. Já para 48 horas, somente foi homogeneizada a mistura antes de determinar as propriedades, sendo apenas uma determinação do teor de ar, verificando-se uma diminuição dos valores do teor de ar incorporado em relação ao tempo de utilização de 0 hora. Desse modo o processo de homogeneização não foi capaz de retomar todo o teor de ar incorporado inicialmente presente na argamassa. Esse comportamento pode ter sido causado pela menor quantidade de água disponível na mistura, conforme apresentado na Figura 3 (valores obtidos da quantidade de água - relação água/materiais secos - e retenção de água), que promove a menor incorporação de ar conforme afirmado por Romano (2013). Apesar de serem armazenadas em ambiente hermeticamente fechado, houve perda de água por evaporação ou consumo de água para hidratação dos compostos. Conforme Guindani (2018) há aditivos estabilizadores que permitem que a etringita se forme normalmente na microestrutura das misturas, causando intertravamento entre as partículas de cimento, observada nos menores valores de relação água/materiais secos das argamassas avaliadas no tempo de utilização de 48 horas (Figura 4). Essa perda de água pode também ter influenciado a retenção de água com o maior valor obtido para a argamassa F8 no tempo de utilização de 48 horas, sendo menor a quantidade de água disponível ou livre. Observa-se na Figura 4 que os valores de retenção de água foram influenciados pelo aditivo estabilizador, sendo superiores ao valor obtido para argamassa de referência, no entanto não foi verificado um padrão de comportamento entre as argamassas no tempo de utilização de 0 hora e 48 horas.

Na Figura 5 apresenta-se o comportamento reológico das argamassas estudadas no tempo de utilização de 0 hora e 48 horas com o deslocamento versus a carga obtido pelo squeeze-flow.

Tabela 4 - Propriedades no estado fresco das argamassas estudadas

\begin{tabular}{|c|c|c|c|c|c|c|c|}
\hline \multirow[b]{2}{*}{ Argamassa } & \multirow{2}{*}{$\begin{array}{c}\text { Teor de } \\
\text { aditivo } \\
(\%)\end{array}$} & \multirow{2}{*}{$\begin{array}{c}\text { Tempo de } \\
\text { utilização } \\
\text { (horas) }\end{array}$} & \multirow{2}{*}{$\begin{array}{c}\begin{array}{c}\text { Indice de } \\
\text { consistência }\end{array} \\
\text { Média }(\mathbf{m m})\end{array}$} & \multicolumn{2}{|c|}{$\begin{array}{c}\text { Densidade de } \\
\text { massa }\end{array}$} & \multicolumn{2}{|c|}{$\begin{array}{c}\text { Teor de ar } \\
\text { incorporado }\end{array}$} \\
\hline & & & & $\begin{array}{l}\text { Média } \\
\left(\mathrm{g} / \mathrm{cm}^{3}\right)\end{array}$ & $\begin{array}{l}\text { CV* } \\
(\%) \\
\end{array}$ & $\begin{array}{c}\text { Média } \\
(\%)\end{array}$ & $\begin{array}{l}\mathrm{CV}^{*} \\
(\%) \\
\end{array}$ \\
\hline FR & 0 & 0 & 23,7 & 1,54 & 0,55 & 31,28 & 1,21 \\
\hline $\mathrm{F} 4$ & 0,4 & $\begin{array}{c}0 \\
48\end{array}$ & $\begin{array}{l}25,7 \\
22,1\end{array}$ & $\begin{array}{l}1,56 \\
1,60\end{array}$ & $\begin{array}{c}0,87 \\
-\end{array}$ & $\begin{array}{l}30,65 \\
28,93\end{array}$ & $\begin{array}{c}1,97 \\
-\end{array}$ \\
\hline F8 & 0,8 & $\begin{array}{c}0 \\
48\end{array}$ & $\begin{array}{l}25,7 \\
20,4\end{array}$ & $\begin{array}{l}1,59 \\
1,63\end{array}$ & $\begin{array}{c}0,82 \\
-\end{array}$ & $\begin{array}{l}29,73 \\
27,27\end{array}$ & $\begin{array}{c}1,93 \\
-\end{array}$ \\
\hline
\end{tabular}

Nota: *coeficiente de variação. 
Figura 4 - Retenção de água e relação água/materiais secos para argamassa estabilizada nos dois tempos de utilização
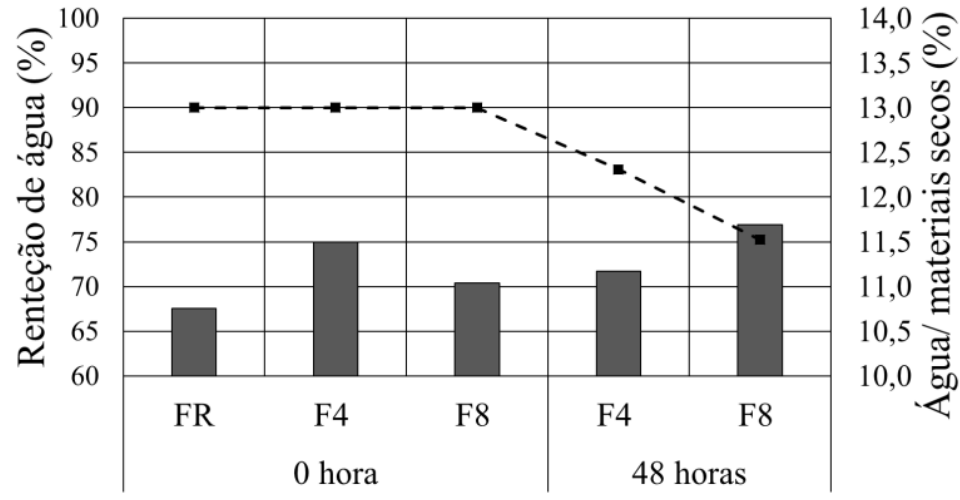

Argamassa estabilizada e tempo de utilização

Retenção de água

-Relação água/ materiais secos

Figura 5 - Carga versus deslocamento obtido pelo squeeze-flow para as argamassas: a) FR e F4; e b) FR e F8

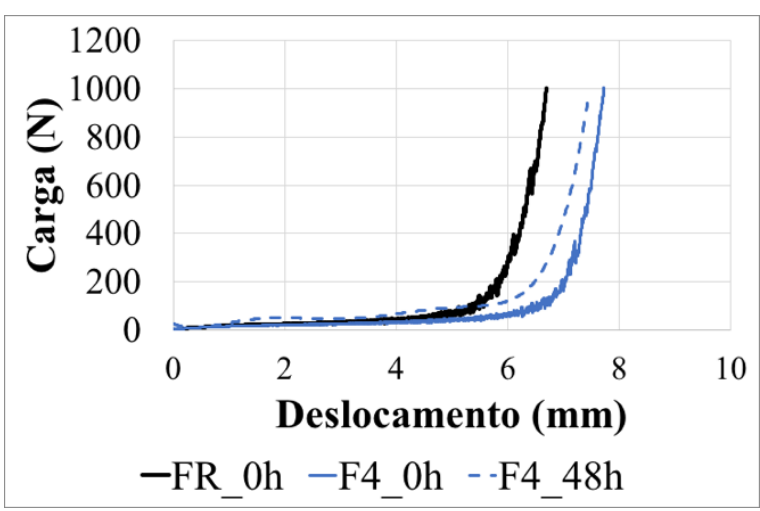

(a)

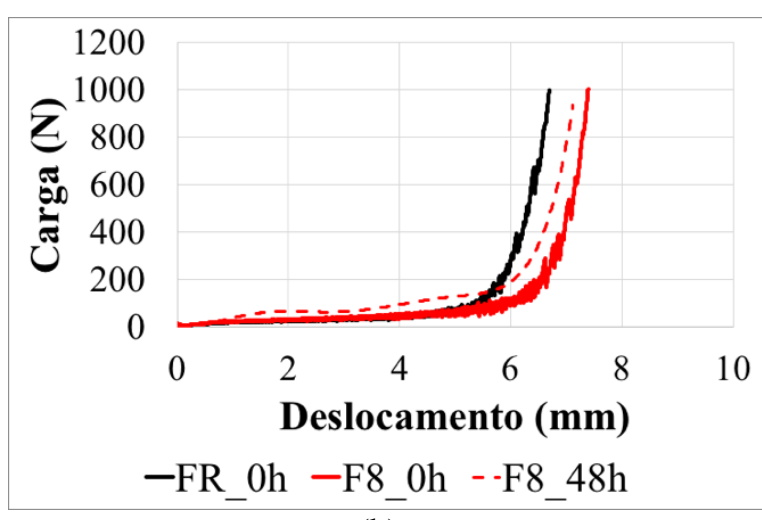

(b)

Observa-se na Figura 5 que a presença do aditivo estabilizador aumentou os valores de deslocamento para a mesma carga (por exemplo, para as argamassas analisadas no tempo de utilização de 0 hora para uma carga de $600 \mathrm{~N}$, o deslocamento para a argamassa FR foi de $6,3 \mathrm{~mm}$, para a argamassa F4 de 7,4 mm e para a argamassa F8 de 7,1 mm). Isso demonstra claramente que as argamassas com aditivo estabilizador se apresentavam mais plásticas, facilitando a movimentação das partículas, o que indica efeito secundário do aditivo.

Nota-se na Figura 5 uma perda de fluidez com o aumento do tempo de utilização das argamassas com aditivo estabilizador comparando o comportamento com 0 hora e 48 horas, tanto pelo comportamento reológico quanto pelo índice de consistência (Tabela 4). Esse comportamento também foi verificado por outros autores (CASALI et al., 2018; MACIOSKI, 2014; FIORAVANTE, 2014; PIVETTA et al., 2016).

A influência do teor de aditivo estabilizador também foi observada na evolução da temperatura com relação ao tempo e, por consequência, no tempo de início de pega das argamassas (Figura 6).

Observa-se na Figura 6 que para a argamassa de referência (FR) o tempo de início de pega foi de 177 minutos. Já para a argamassa F4 o tempo de utilização influenciou no tempo de início de pega, sendo obtidos os valores de 3.696 minutos para a argamassa F4 - 0 hora e 3.626 minutos para a argamassa F4 - 48 horas. Essa diminuição do tempo de início de pega pode ter ocorrido devido à perda de água ocorrida entre 0 hora e 48 horas, conforme mencionado anteriormente. O mesmo comportamento foi observado para a argamassa F8 - 0 hora (tempo de início de pega 8.600 minutos) e F8 - 48 horas (tempo de início de pega 8.480 minutos). 
Na Figura 7 são apresentados os valores médios obtidos de resistência à tração na flexãoe resistência à compressão com a evolução do tempo das argamassas estudadas.

Para a resistência à tração na flexão houve um pequeno aumento ao longo do tempo com um alto coeficiente de correlação da regressão logarítmica $\left(\mathrm{R}^{2}\right.$ acima de 0,79$)$ (Figuras $7 \mathrm{a}$ e $7 \mathrm{~b}$ ). Os maiores valores de resistência à tração obtidos foram para a argamassa F4 no tempo de utilização de 0 hora, e os menores valores para a argamassa F8 no tempo de utilização de 0 hora. Esse mesmo comportamento foi observado para os valores obtidos de resistência à compressão (Figuras 7c e 7d). No entanto, para as argamassas F4 nos dois tempos de utilização, 0 e 48 horas, e para a argamassa FR, praticamente não houve crescimento da resistência a partir dos 14 dias e por esse motivo o coeficiente de correlação da regressão logarítmica não foi significativo quanto ao obtido para a resistência à tração na flexão. Porém, para as argamassas F8 nos dois tempos de utilização, 0 hora e 48 horas, houve um aumento gradual de resistência à compressão conforme a idade, com exceção da argamassa F8 no tempo de 0 hora aos 14 dias. Para essas duas argamassas foram obtidos médios coeficientes de correlação das regressões logarítmicas (Figura 7d).

Figura 6 - Temperatura versus tempo para as argamassas nos dois tempos de utilização

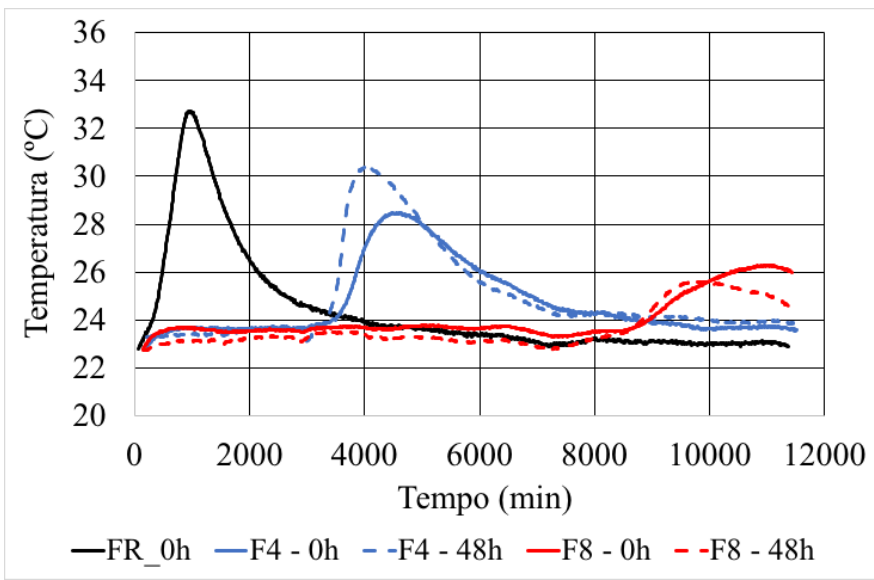

Figura 7 - Evolução ao longo do tempo: (a) resistência à tração na flexão para as argamassas FR e F4; (b) resistência à tração na flexão para as argamassas FR e F8; (c) resistência à compressão para as argamassas FR e F4; e (d) resistência à compressão para as argamassas FR e F8
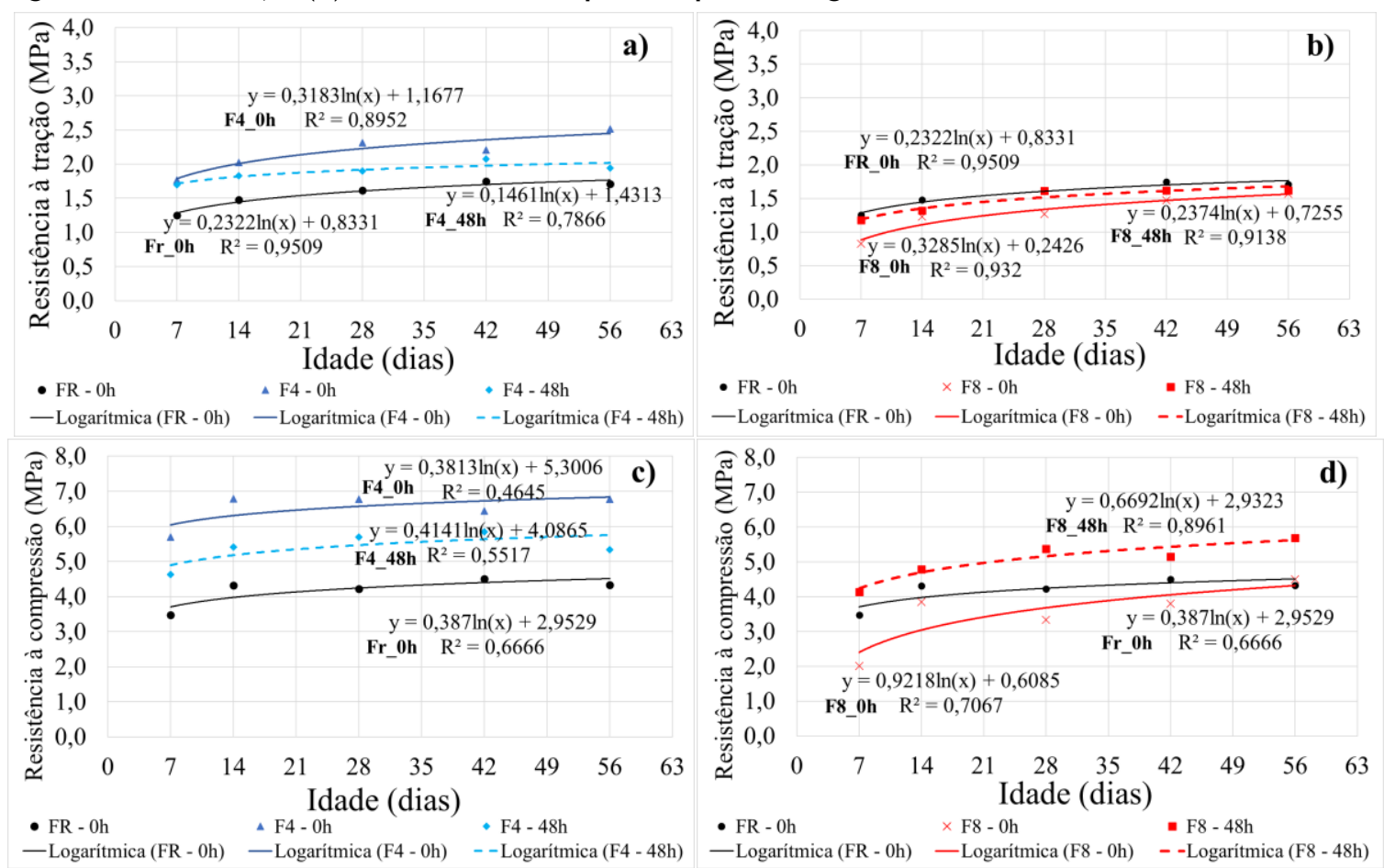

272 Casali, J. M.; Mees, S.; Oliveira, A. L. de; Betioli, A. M.; Calçada, L. M. 
Observa-se na Figura 7 que houve influência positiva do aditivo estabilizador nas resistências, sendo mais acentuada para resistência à compressão. Para a argamassa F4 no tempo de utilização de 0 hora, em comparação ao obtido da argamassa FR, provavelmente houve melhor compactação devido ao efeito plastificante do aditivo, que facilita a movimentação das partículas, conforme o comportamento reológico (Figura 5a), e menor teor de ar incorporado (Tabela 4).

Em relação ao teor de aditivo, observa-se nas Figuras 7c e 7d que os menores valores obtidos de resistência foram para a argamassa F8 no tempo de utilização de 0 hora. No entanto, somente aos 56 dias obteve-se resistência semelhante à argamassa de referência, não sendo observada diferença significativa entre essas duas argamassas nessa idade (com 95\% de nível de confiabilidade).

Já o tempo de utilização em todas as idades analisadas influenciou negativamente para as argamassas F4, porém para a argamassa F8 influenciou positivamente na resistência à compressão. Nesse caso houve a influência de dois efeitos: do teor de aditivo utilizado (efeito plastificante melhorando a compactação) e do tempo de utilização (menor relação água/materiais secos) (Figura 4).

O módulo de elasticidade dinâmico e a densidade de massa aparente no estado endurecido são apresentados na Figura 8.

Nota-se na Figura 8a que os maiores valores de módulo de elasticidade foram obtidos para a argamassa F4 no tempo de utilização de 0 hora, sendo essa argamassa aquela que apresentou também os maiores valores de resistência à compressão. Assim, verificou-se que os valores médios de módulo de elasticidade apresentaram boa correlação com os valores médios obtidos de resistência à compressão (Figura 9a). A correlação é melhor quando são utilizados os valores individuais das argamassas FR, F4 e F8 no tempo de utilização de 0 hora. Na Figura 9 b são apresentados os coeficientes de correlação linear para essas argamassas nos valores individuais para 7 dias, 14 dias e 28 dias. Para a resistência à tração na flexão não foi obtida a mesma correlação e nem para a densidade de massa aparente no estado endurecido, sendo os maiores valores obtidos para a argamassa F8 no tempo de utilização de 48 horas (Figura 9b).

Figure 8 - (a) Módulo de elasticidade dinâmico e (b) densidade de massa aparente no estado endurecido para todas as argamassas

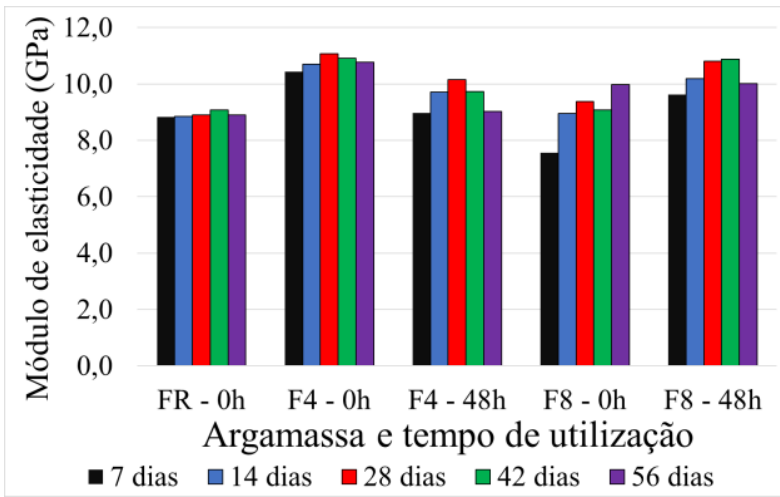

(a)

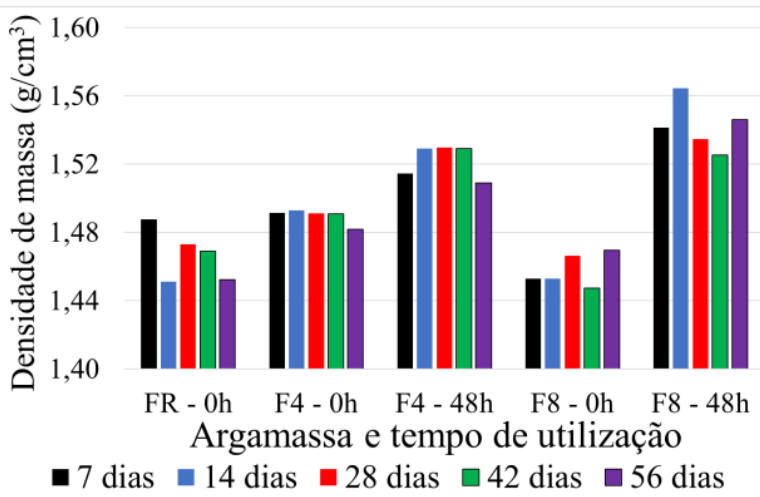

(b)

Figure 9 - Correlação entre modulo de elasticidade dinâmico versus resistência à tração e compressão

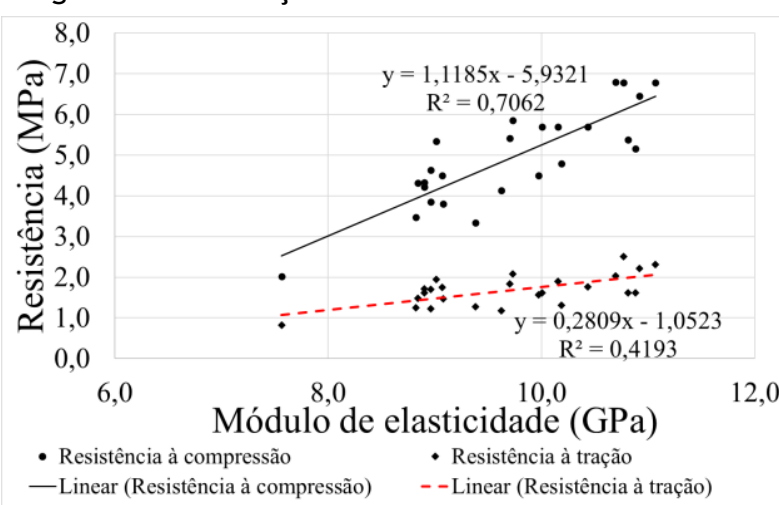

(a) Valores médios

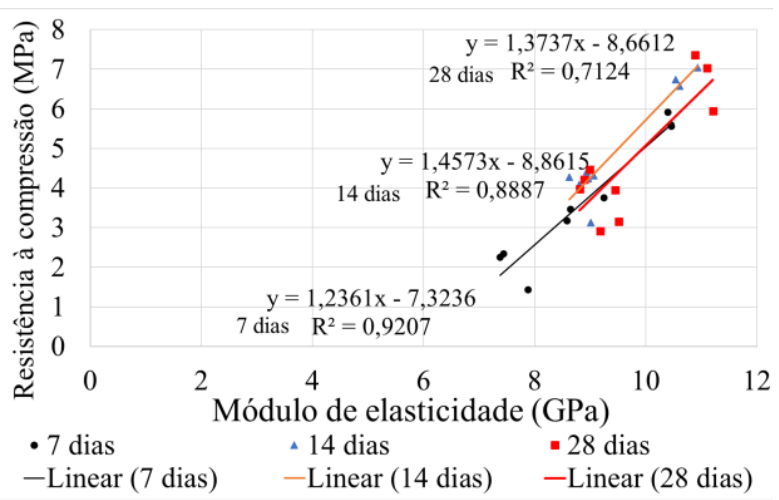

b) Valores individuais 


\section{Avaliação do grau de hidratação das argamassas estabilizadas}

Na Figura 10 são apresentados os resultados obtidos da quantidade de água evaporável e dos primeiros compostos em relação à perda de massa a $1.000{ }^{\circ} \mathrm{C}(\mathrm{EW})$ obtidos por perda ao fogo para as argamassas estudadas.

Nota-se na Figura 10 uma tendência de redução da quantidade de água evaporável e dos primeiros compostos (EW) ao longo do tempo, sendo observados médios a altos coeficientes de correlações principalmente para a argamassa F4 no tempo de utilização de 0 hora e argamassa F8 no tempo de utilização de 0 hora. Esse comportamento possivelmente foi em função da perda de água por evaporação ou por consumo de água pelos primeiros compostos.

A quantidade de água quimicamente combinada dos hidratos entre $100{ }^{\circ} \mathrm{C}$ e a temperatura final do pico característico ao hidróxido de cálcio em relação à perda de massa a $1.000{ }^{\circ} \mathrm{C}(\mathrm{TH})$ é apresentada na Figura 11.

Observa-se na Figura 11, para a argamassa FR, uma tendência de redução da quantidade de água quimicamente combinada relativa ao hidróxido de cálcio $(\mathrm{TH})$ ao longo do tempo com altos coeficientes de correlação. Esse comportamento não era esperado uma vez que as resistências à compressão aumentaram ao longo do tempo (Figura 7). Já para as demais argamassas o parâmetro praticamente se manteve constante ao longo do tempo e com baixa correlação, no entanto foi observada uma influência do teor de aditivo estabilizador nos valores obtidos de TH (Figura 12).

Nota-se na Figura 12 que houve uma diminuição dos valores de TH com aumento do teor de aditivo estabilizador, sendo obtidas boas correlações lineares com exceção da idade de 42 dias. Isso indica que o aditivo influencia no grau de hidratação, formando menos compostos hidratados para as argamassas F8. No entanto, isso não se refletiu na resistência à compressão, pois não foi verificada boa correlação linear entre o parâmetro de TH e a resistência à compressão, com exceção da argamassa FR (Figura 12a). Isso demostra que a resistência à compressão possivelmente foi influenciada mais pelo teor de ar incorporado e fluidez no estado fresco, facilitando a movimentação das partículas e consequentemente modificando o empacotamento dos grãos no estado endurecido, e menos influenciada pelo grau de hidratação obtido por meio da quantidade de água combinada dos hidratos. Porém, foram observados médios coeficientes de correlação linear entre a resistência à compressão e o parâmetro EW (quantidade de água livre e primeiros compostos) para as argamassas estudadas (Figura 13a e Figura 13b), com exceção da argamassa F4 no tempo de utilização de 0 hora. Observa-se na Figura 13a e Figura 13b uma tendência de que quanto maior o parâmetro EW, menor a resistência à compressão, podendo inclusive ter influenciado o ensaio de resistência à compressão em função da umidade do corpo de prova.

Observa-se que os resultados apresentados nas Figuras 10, 11 e 12 referentes ao grau de hidratação por perda ao fogo foram influenciados pela idade, tipo de argamassa e teor de aditivo estabilizador (Figura 11, Figura 12 e Figura 13). Cabe ressaltar que o ensaio de perda ao fogo é relativamente simples e podem-se obter boas correlações que serão comparadas com os resultados obtidos pela análise termogravimétrica e difração de raios $\mathrm{X}$ (apresentados a seguir).

As Figuras 14a a 14e apresentam as curvas de perda de massa TG e DTG das argamassas estudadas com 28 dias e as Figuras 15a a 15e apresentam as curvas de perda de massa TG e DTG das argamassas estudadas com 56 dias.

Observa-se na Figura 14 e Figura 15 que para todos os casos foi possível observar a perda de massa na desidratação do hidróxido de cálcio $\left(\mathrm{Ca}(\mathrm{OH})_{2}\right)$ ou portlandita $\left(400{ }^{\circ} \mathrm{C}\right.$ a $\left.500{ }^{\circ} \mathrm{C}\right)$ e decomposição do carbonato de cálcio e volatização do anidrido carbônico $\left(500{ }^{\circ} \mathrm{C}\right.$ a $\left.1.000{ }^{\circ} \mathrm{C}\right)$.

Assim, foram calculados o teor de $\mathrm{Ca}(\mathrm{OH})_{2}$ e o teor de $\mathrm{CaCO}_{3}$ determinados pela aplicação de fatores relacionando as massas moleculares dos compostos, conforme descrito nas Equações 3 e 4, e apresentado na Tabela 5. Além disso, são apresentados os valores de perda de água livre e dos primeiros compostos $\left(20^{\circ} \mathrm{C}\right.$ a $\left.105{ }^{\circ} \mathrm{C}\right)$ e da decomposição dos compostos hidratos $\left(105{ }^{\circ} \mathrm{C}\right.$ a $\left.400{ }^{\circ} \mathrm{C}\right)$. Todos os parâmetros são apresentados nas duas idades para todas as argamassas. 
Figura 10 - Quantidade de água evaporável e dos primeiros compostos (EW) obtidos por perda ao fogo

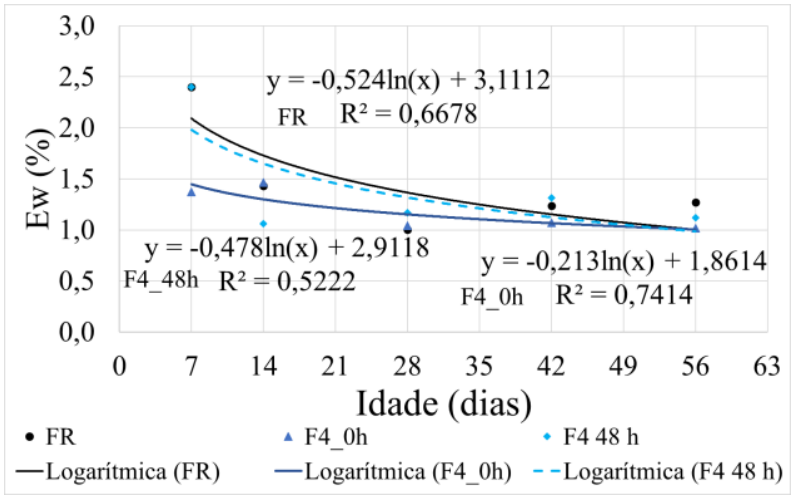

(a) Argamassas FR e F4

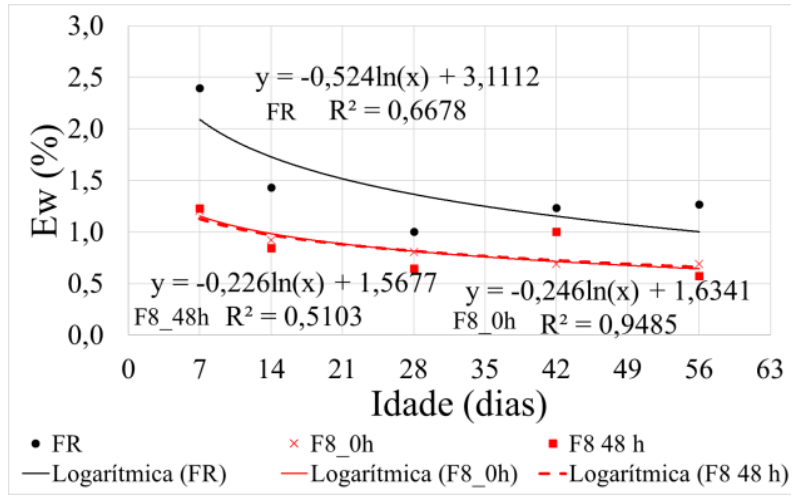

(b) Argamassas FR e F8

Figura 11 - Quantidade de água quimicamente combinada dos hidratos entre 105 oC e a temperatura final do pico característico ao hidróxido de cálcio (TH)

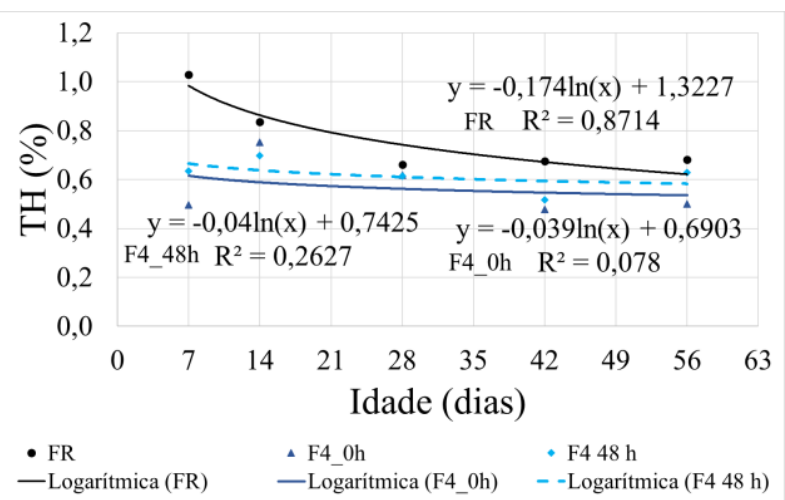

(a) Argamassas FR e F4

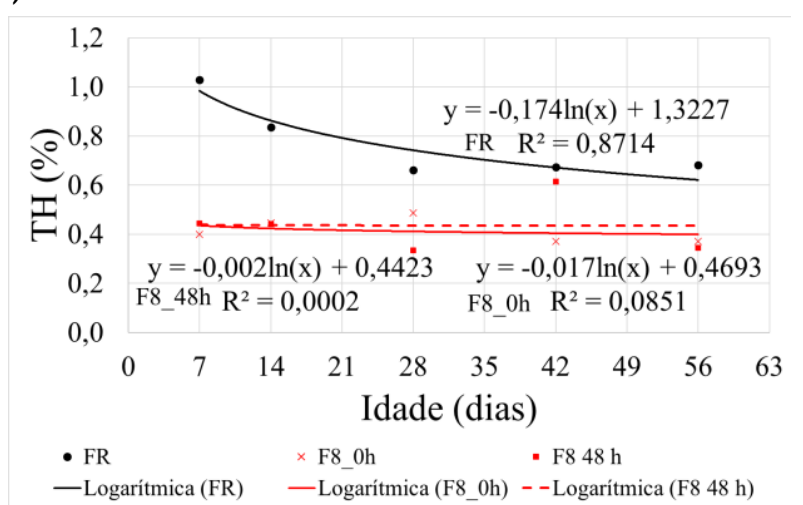

(b) Argamassas FR e F8

Figura 12 - TH versus teor de aditivo estabilizador de hidratação

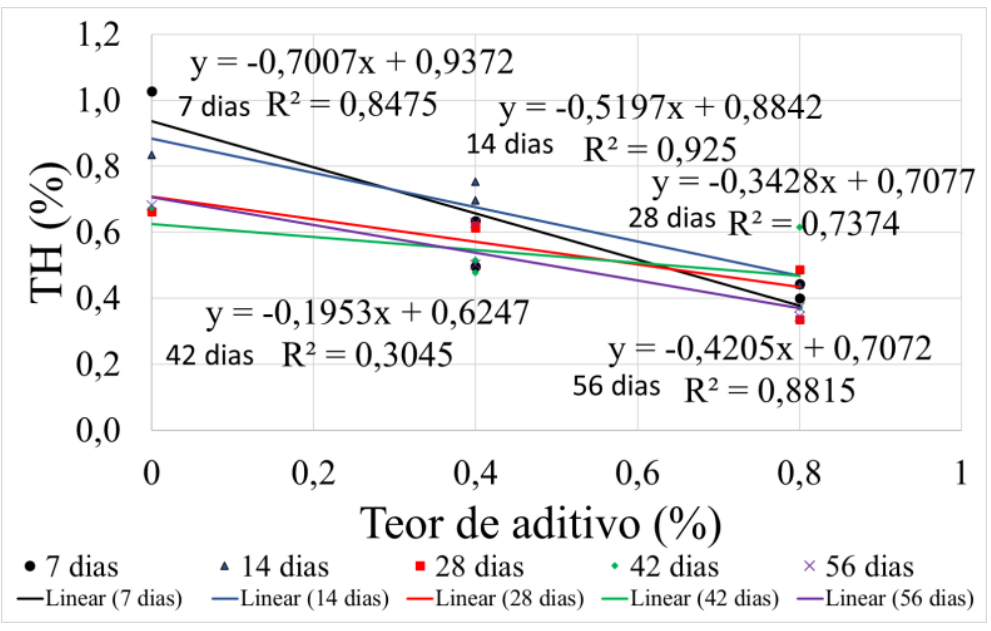


Figura 13 - Correlação entre EW e TH e a resistência à compreensão: a) argamassas FR e F4, e b) argamassas F8

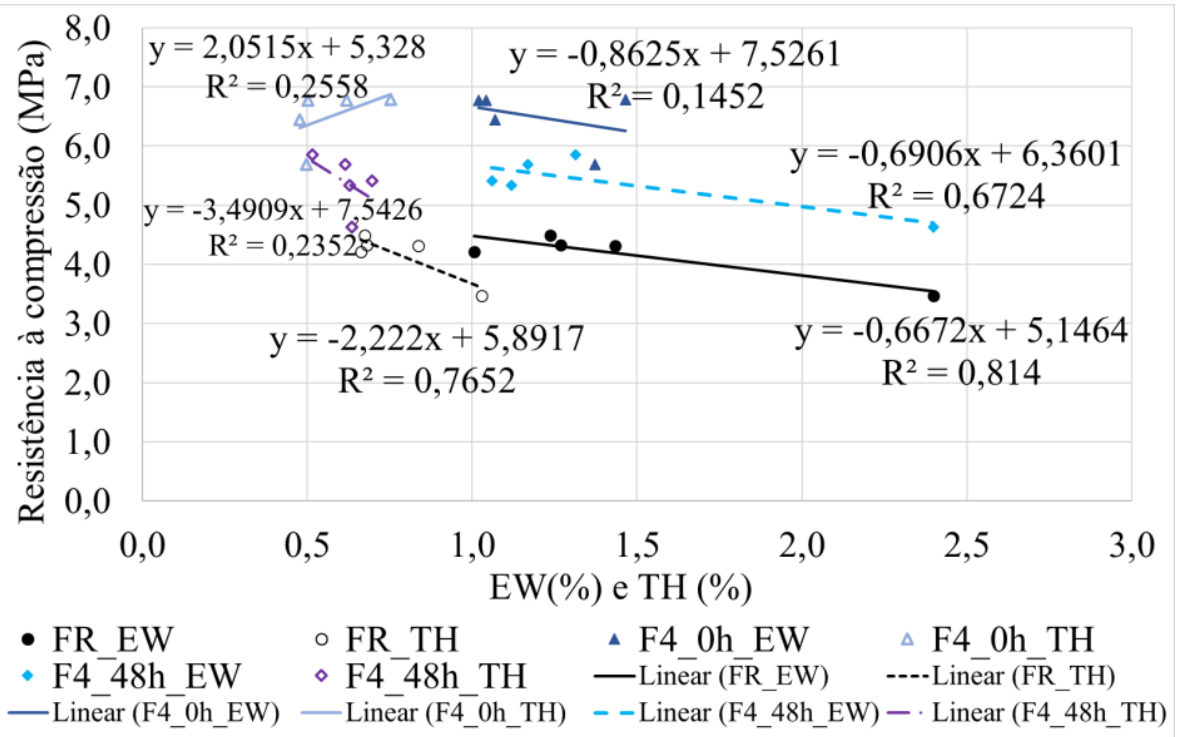

(a) Argamassas FR e F4

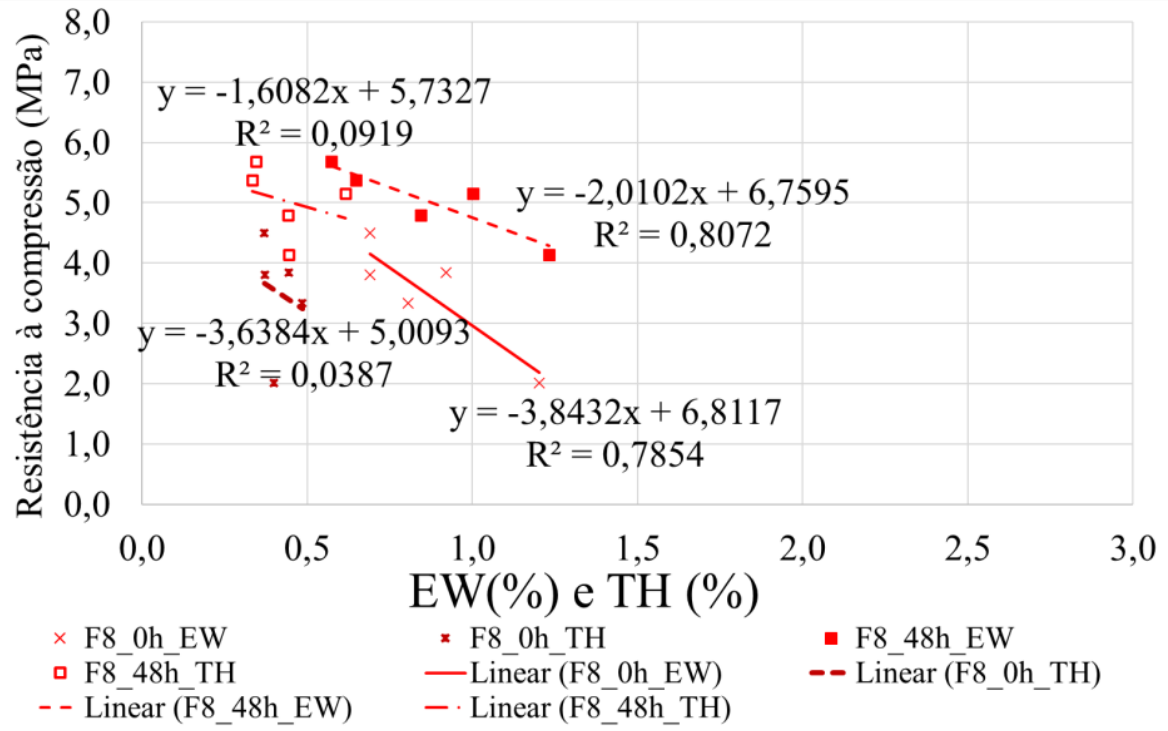

(b) Argamassas F8 
Figura 14 - Perda de massa obtida pela análise termogravimétrica aos 28 dias

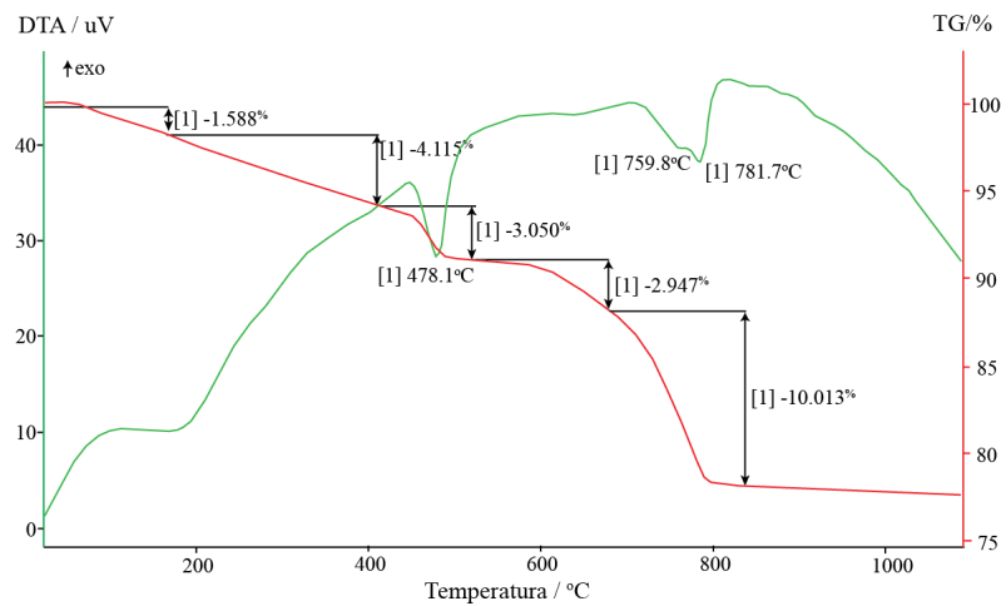

(a) Argamassa FR

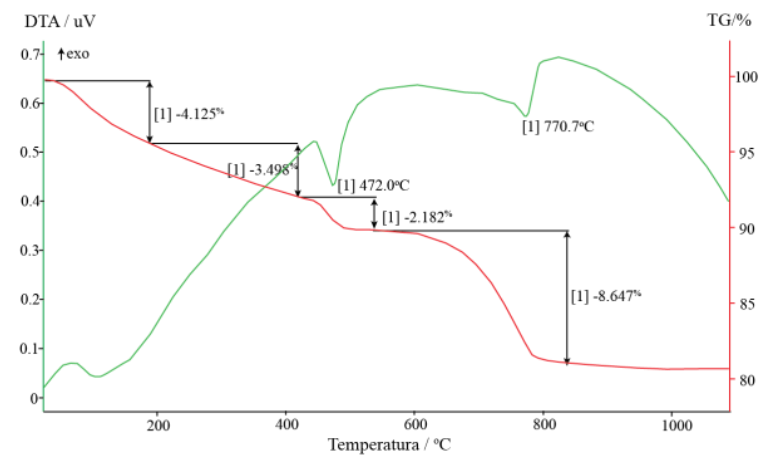

(b) Argamassa F4 com tempo de utilização de 0 hora

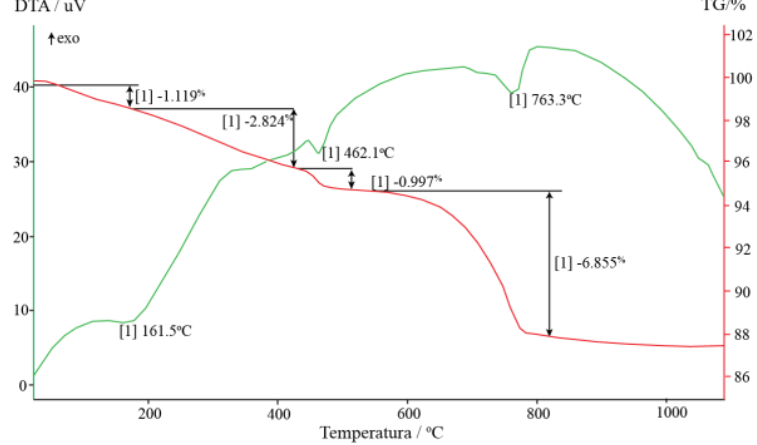

(d) Argamassa F8 com tempo de utilização de 0 hora

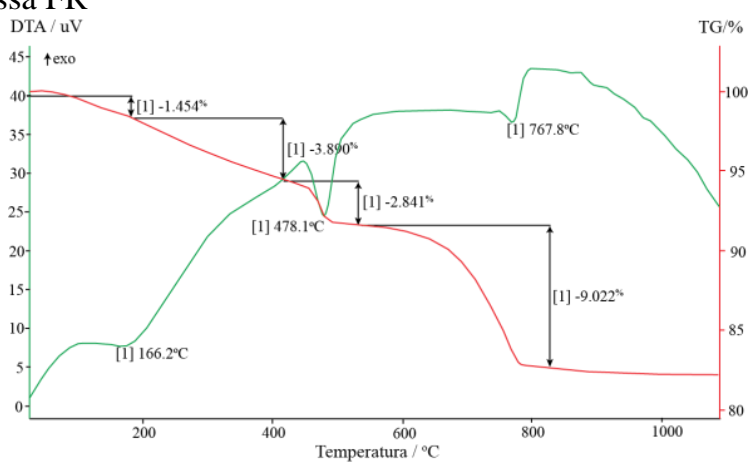

(c) Com tempo de utilização de 48 horas

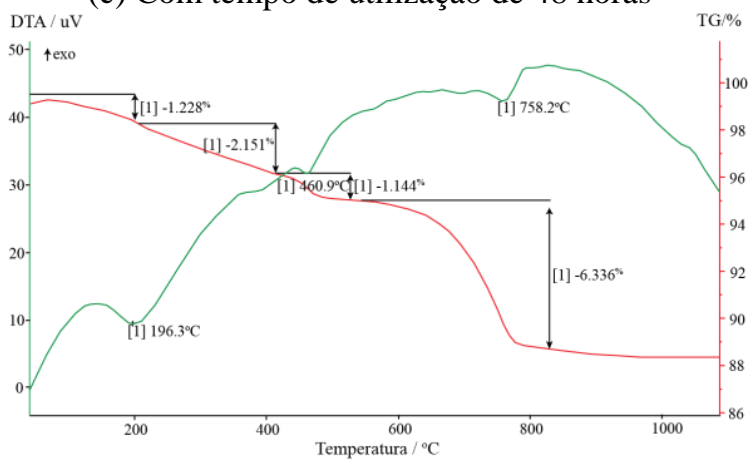

(e) Com tempo de utilização de 48 horas 
Figura 15 - Perda de massa obtida pela análise termogravimétrica aos 56 dias

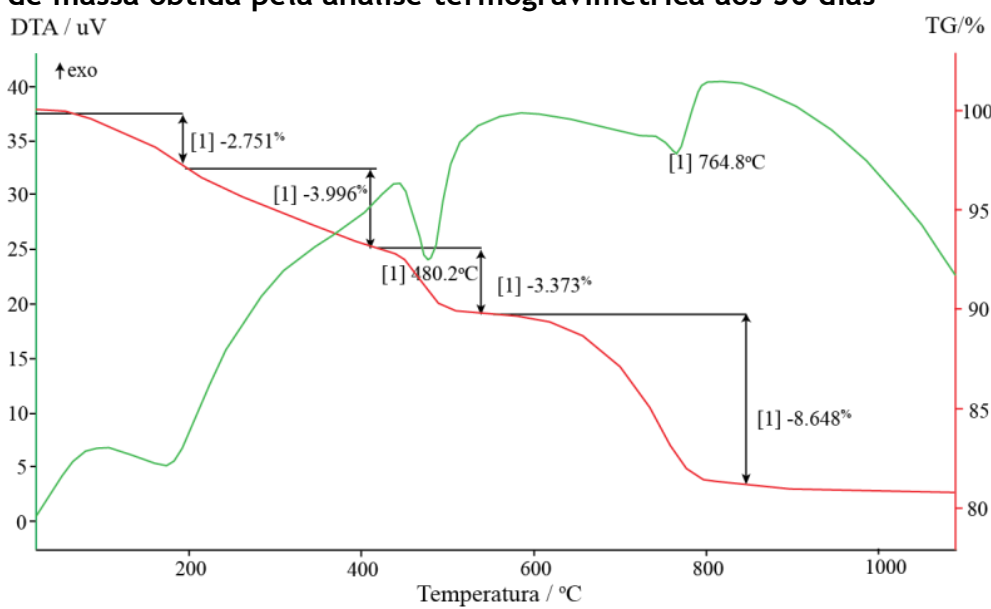

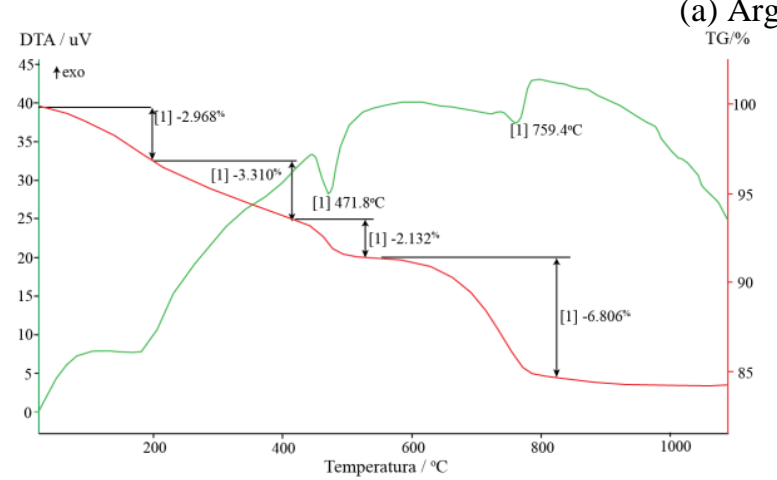

(b) Argamassa F4 com tempo de utilização de 0 hora

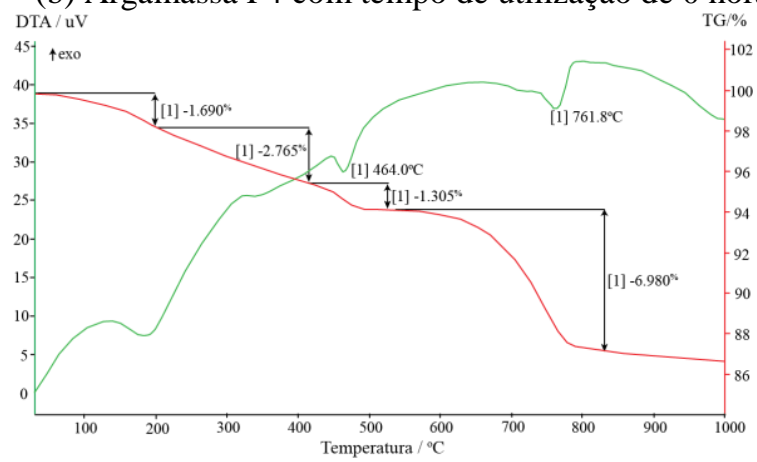

(d) Argamassa F8 com tempo de utilização de 0 hora

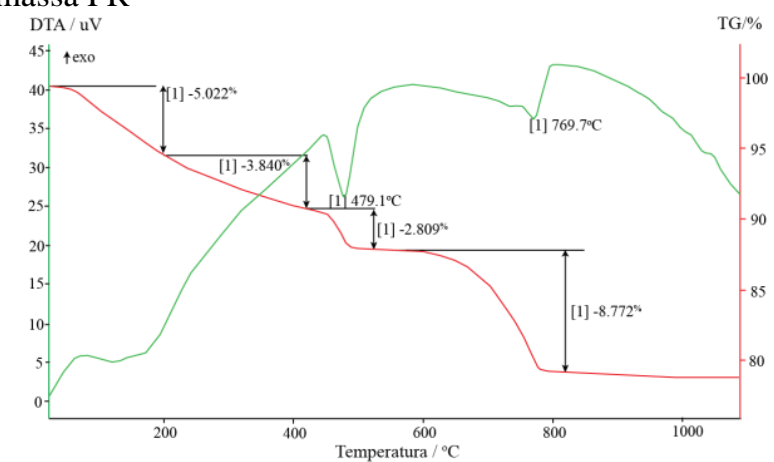

(c) Com tempo de utilização de 48 horas

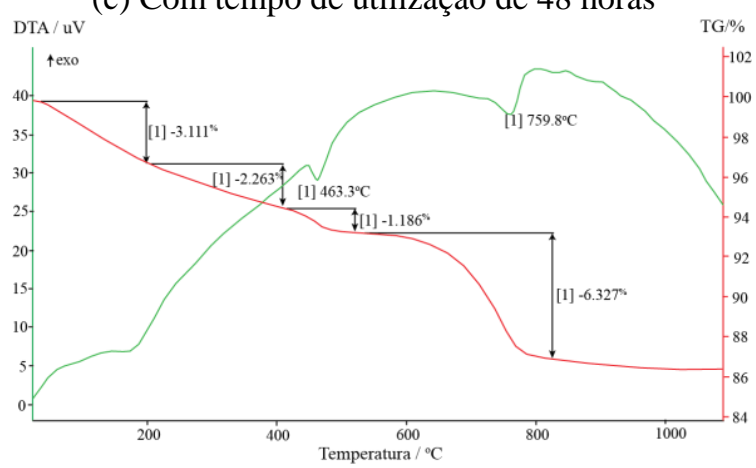

(e) Com tempo de utilização de 48 horas

Tabela 5 - Parâmetros obtidos pela análise termogravimétrica aos 28 dias e 56 dias

\begin{tabular}{|c|c|c|c|c|c|c|c|c|}
\hline \multirow{4}{*}{ Arg } & \multicolumn{4}{|c|}{28 dias } & \multicolumn{4}{|c|}{56 dias } \\
\hline & \multirow{2}{*}{$\begin{array}{c}\text { ALC } \\
(\%)\end{array}$} & \multicolumn{3}{|c|}{ Água quimicamente ligada (\%) } & \multirow[b]{2}{*}{$\begin{array}{c}\text { ALC } \\
(\%)\end{array}$} & \multicolumn{3}{|c|}{ Água quimicamente ligada (\%) } \\
\hline & & $\begin{array}{l}\text { Compostos } \\
\text { hidratados }\end{array}$ & $\begin{array}{c}\mathrm{Ca}(\mathrm{OH})_{2} \\
(\mathrm{x} 4,11)\end{array}$ & $\begin{array}{l}\mathrm{CaCO}_{3} \\
(\mathbf{x} 2,27) \\
\end{array}$ & & $\begin{array}{l}\text { Compostos } \\
\text { hidratados }\end{array}$ & $\begin{array}{c}\mathrm{Ca}(\mathrm{OH})_{2} \\
(\mathrm{x} 4,11)\end{array}$ & $\begin{array}{l}\mathrm{CaCO}_{3} \\
(\mathrm{x} 2,27) \\
\end{array}$ \\
\hline & $\begin{array}{c}20^{\circ} \mathrm{C} \\
\mathbf{a} \\
105^{\circ} \mathrm{C}\end{array}$ & $\begin{array}{c}105^{\circ} \mathrm{C} \mathrm{a} \\
400^{\circ} \mathrm{C}\end{array}$ & $\begin{array}{c}400{ }^{\circ} \mathrm{C} \text { a } \\
500{ }^{\circ} \mathrm{C}\end{array}$ & $\begin{array}{l}500{ }^{\circ} \mathrm{C} \text { a } \\
1.000{ }^{\circ} \mathrm{C}\end{array}$ & $\begin{array}{l}20{ }^{\circ} \mathrm{C} \text { a } \\
105^{\circ} \mathrm{C}\end{array}$ & $\begin{array}{c}105^{\circ} \mathrm{C} \text { a } \\
400^{\circ} \mathrm{C}\end{array}$ & $\begin{array}{c}400{ }^{\circ} \mathbf{C} \mathbf{a} \\
500{ }^{\circ} \mathbf{C}\end{array}$ & $\begin{array}{l}500{ }^{\circ} \mathrm{C} \text { a } \\
1.000{ }^{\circ} \mathrm{C}\end{array}$ \\
\hline FR_0h & 0,38 & 4,91 & 12,54 & 22,72 & 0,38 & 5,37 & 13,85 & 19,64 \\
\hline F4_0h & 1,38 & 5,56 & 8,96 & 19,63 & 0,82 & 4,80 & 8,75 & 15,46 \\
\hline F4_48h & 0,27 & 4,62 & 11,67 & 20,47 & 1,77 & 6,35 & 11,55 & 19,91 \\
\hline F8_0h & 0,42 & 3,38 & 4,07 & 15,55 & 0,28 & 3,61 & 5,34 & 15,84 \\
\hline F8_48h & 0,31 & 2,76 & 4,69 & 14,39 & 1,26 & 3,82 & 4,89 & 14,37 \\
\hline
\end{tabular}

278 Casali, J. M.; Mees, S.; Oliveira, A. L. de; Betioli, A. M.; Calçada, L. M. 
Observa-se na Tabela 5 que os valores obtidos de perda de massa referente à desidratação do hidróxido de cálcio $\left(\mathrm{Ca}(\mathrm{OH})_{2}\right)$ aos 28 dias e aos 56 dias aumentaram ou foram praticamente constantes para as argamassas. E para a decomposição do carbonato de cálcio e volatização do anidrido carbônico $\left(\mathrm{CaCO}_{3}\right)$ os valores diminuíram ou se mantiveram constantes de 28 dias para os valores de 56 dias. No entanto, para os dois parâmetros foi verificada a influência do teor de aditivo apresentado na Figura 16, conforme já havia sido verificada pelo método de perda ao fogo apresentado anteriormente.

Nota-se na Figura 16a e na Tabela 5 que os valores obtidos de perda de massa da decomposição do carbonato de cálcio diminuíram conforme o aumento do teor de aditivo estabilizador e aumentaram conforme a idade obtendo uma boa correlação linear. Também foi observada boa correlação linear da decomposição do carbonato de cálcio aos 28 dias (Figura 16b).

O comportamento da Figura 16 demonstra que o teor de aditivo estabilizador de hidratação modifica as reações de hidratação do cimento Portland e isso, novamente, não foi refletido no comportamento da resistência à compressão (Figura 17), conforme os valores obtidos de perda ao fogo.

Os resultados da Figura 17 demonstram novamente que o grau de hidratação obtido na perda de massa da decomposição dos compostos hidratados influenciou muito pouco na resistência à compressão. Conforme já mencionado, possivelmente a resistência à compressão foi influenciada mais pelo teor de ar incorporado e fluidez no estado fresco, facilitando a movimentação entre as partículas e consequentemente modificando a compactação no estado endurecido.

Os dados obtidos do grau de hidratação verificados por perda ao fogo e análise termogravimétrica foram complementados com os valores obtidos da quantificação das fases cristalinas obtidas por meio da difração de raios X para as argamassas FR, F4 e F8 no tempo de utilização de 0 hora e 56 dias de idade, apresentados na Tabela 6 e Figura 18. Na Figura 18 foram apresentados somente os picos de identificação da portlandita, que foi o composto utilizado para avaliação do grau de hidratação nos demais métodos apresentados.

Figura 16 - Perda de massa aos 28 dias e aos 56 dias

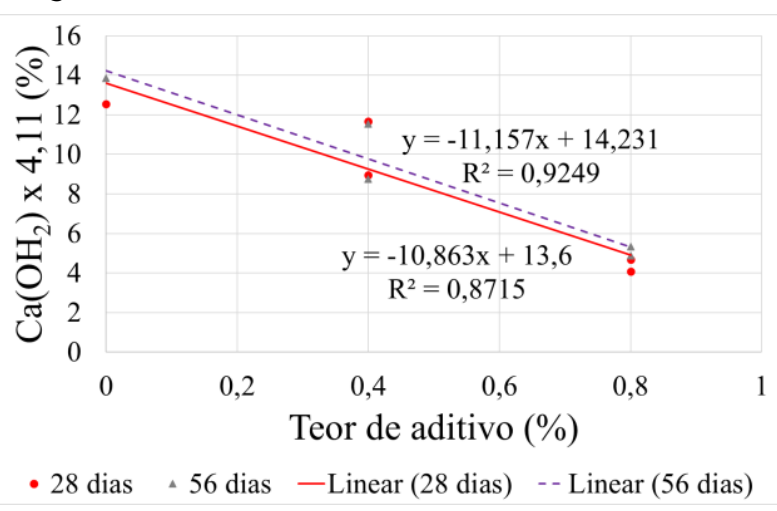

(a) Desidratação de cálcio $(\mathrm{Ca}(\mathrm{OH}) 2)$

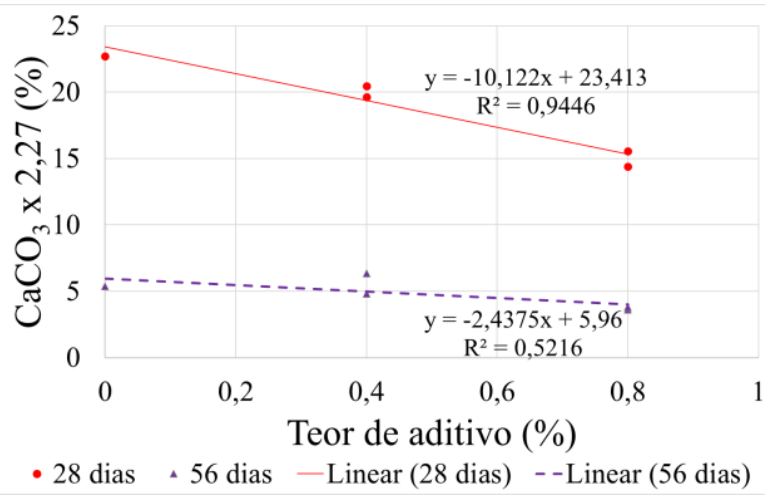

(b) Decomposição do carbonato de cálcio (CaCO3)

Figura 17 - Perda de massa da decomposição dos compostos hidratados versus resistência à compressão

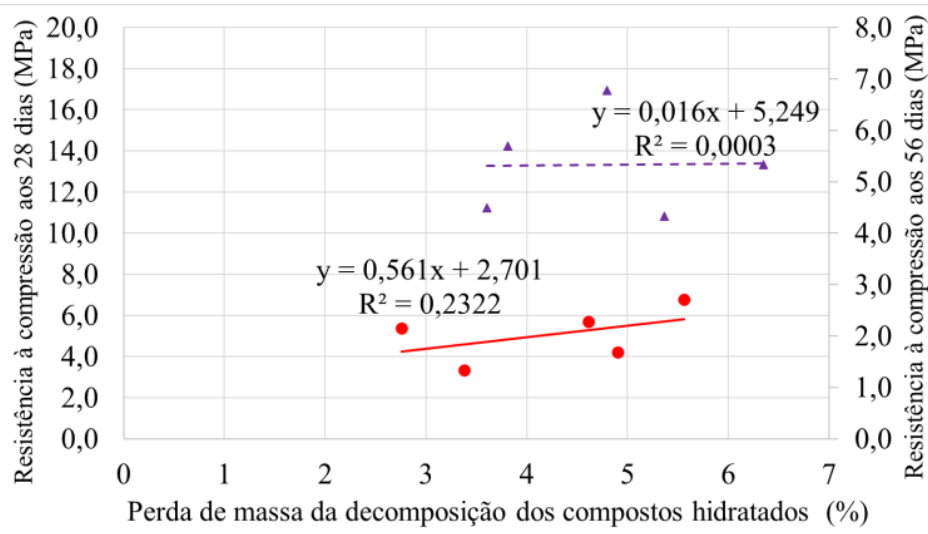

- 28 dias $\triangle 56$ dias - Linear (28 dias) - - Linear (56 dias) 
Tabela 6 - Quantificação das fases cristalinas obtidas pordifração de raios $X$ aos 56 dias

\begin{tabular}{l|c|c|c}
\hline & \multicolumn{3}{|c}{ Quantificação (\%) } \\
\hline Fase Identificada & Argamassa FR_0h & Argamassa F4_0h & Argamassa F8_0h \\
\hline Quartzo & 7,91 & 7,8 & 7,26 \\
Alita & 56,62 & 61,58 & 62,37 \\
Belita & 7,99 & 9,55 & 9,61 \\
Calcita & 14,80 & 12,72 & 13,16 \\
Portlandita & 12,66 & 8,51 & 7,59 \\
\hline
\end{tabular}

Figura 18 - Resultados obtidos das fases cristalinas por difração de raios $\mathrm{X}$ no tempo de utilização de 0 hora aos 56 dias: (a) argamassa FR, (b) argamassa F4 e (c) argamassa F8
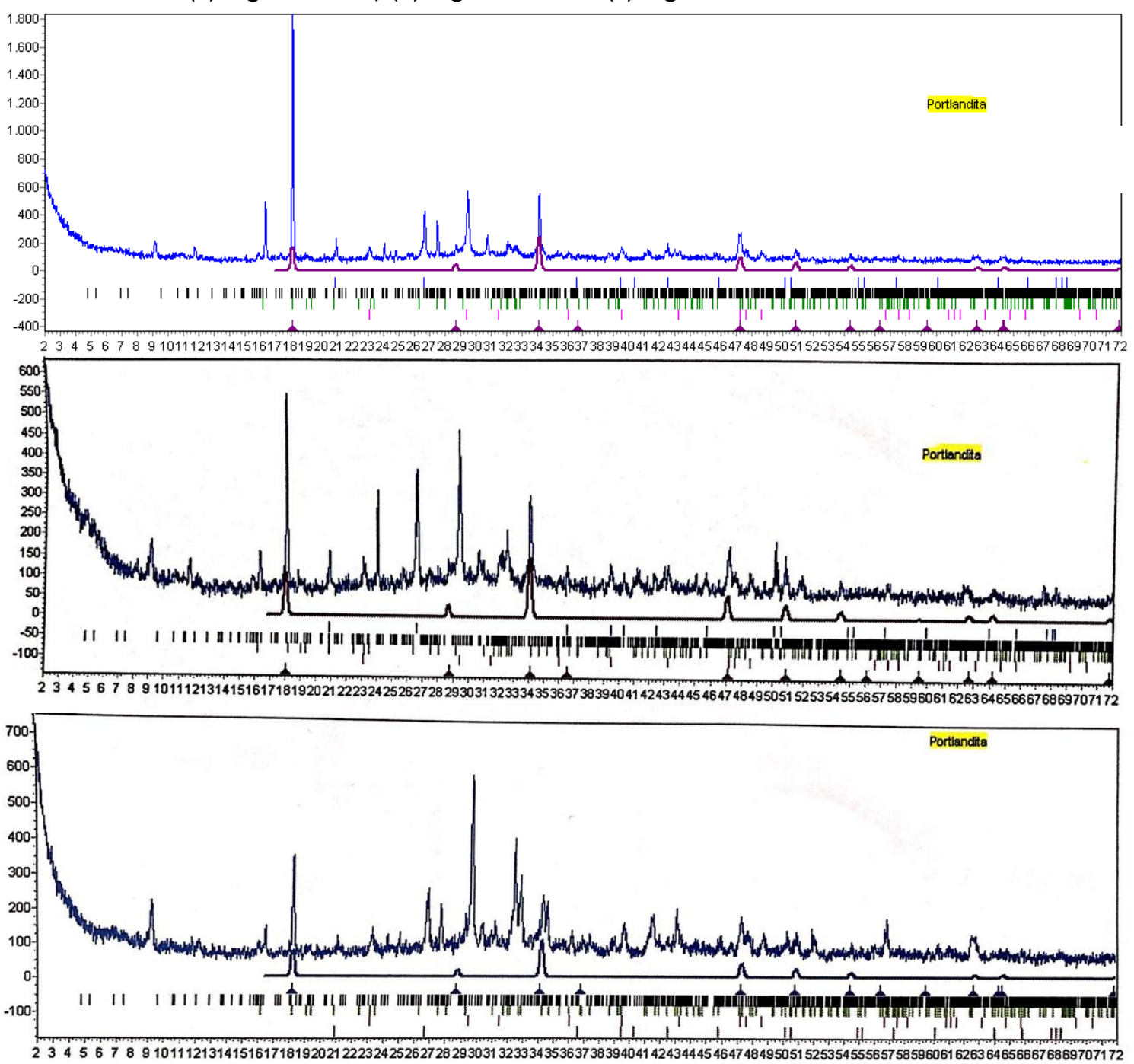

Observa-se na Tabela 6 que os valores foram influenciados pelo teor de aditivo estabilizador, em que o maior valor de portlandita foi obtido para a argamassa FR e o menor valor obtido para a argamassa F8. Além disso, para a argamassa FR foi consumido mais alita e belita $(64,61 \%)$ do que para a argamassa F4 $(71,13 \%)$ e para a F8 $(71,98 \%)$.

Os resultados demonstram que o grau de hidratação foi influenciado pelo teor de aditivo e pela idade e que não refletiu na resistência à compressão.

280 Casali, J. M.; Mees, S.; Oliveira, A. L. de; Betioli, A. M.; Calçada, L. M. 


\section{Conclusão}

Com os resultados obtidos, verificou-se que o teor de aditivo estabilizador de hidratação e o tempo de utilização influenciaram nas propriedades do estado fresco das argamassas: aumento no teor de ar incorporado, aumento da fluidez, aumento da retenção de água e aumento do tempo de início de pega.

Também foi observada uma influência do teor de aditivo, do tempo de utilização e da idade nas propriedades do estado endurecido, no qual os maiores valores de resistência à compressão foram obtidos para a argamassa F4 no tempo de utilização de 0 hora e as menores resistências à compressão para a argamassa F8 no tempo de utilização de 0 hora. Foram obtidas boas correlações lineares entre o módulo de elasticidade dinâmico e a resistência à compressão.

Independentemente do método utilizado de determinação do grau de hidratação, sendo o método de perda ao fogo o mais simples deles, a mesma tendência foi observada para essa propriedade pelos diferentes métodos. Os resultados indicam que a determinação do grau de hidratação em argamassa poderia ser utilizada para a avaliação do material aplicado, já em estado endurecido, como, por exemplo, em revestimento.

Para os três métodos de determinação do grau de hidratação foi verificada uma influência da idade e do teor de aditivo estabilizador ao longo do tempo, em que os maiores graus de hidratação foram obtidos para a argamassa FR, seguidos da argamassa F4 e finalmente da argamassa F8. No entanto, não foi possível correlacionar grau de hidratação com a resistência à compressão. Provavelmente a resistência à compressão foi influenciada mais pelo teor de ar incorporado e fluidez no estado fresco, facilitando a movimentação das partículas e consequentemente modificando a compactação no estado endurecido, do que pelo grau de hidratação.

Os resultados contribuem para o conhecimento das argamassas estabilizadas e demonstram que as resistências são influenciadas por outros fatores, e não somente pelo grau de hidratação.

\section{Referências}

ANTONIAZZI, J. P. O efeito dos aditivos incorporador de ar e estabilizador de hidratação nas propriedades das argamassas estabilizadas. Santa Maria, 2019. 258 f. Tese (Doutorado em Engenharia Civil) - Centro de Tecnologia, Universidade Federal de Santa Maria, Santa Maria, 2019.

ASSOCIAÇÃO BRASILEIRA DE NORMAS TÉCNICAS.NBR 13276: argamassa para assentamento e revestimento de paredes e tetos: determinação do índice de consistência. Rio de Janeiro, 2016.

ASSOCIAÇÃO BRASILEIRA DE NORMAS TÉCNICAS. NBR 13277: argamassa para assentamento e revestimento de paredes e tetos: determinação da retenção de água. Rio de Janeiro, 2005a.

ASSOCIAÇÃO BRASILEIRA DE NORMAS TÉCNICAS. NBR 13278: argamassa para assentamento e revestimento de paredes e tetos: determinação da densidade de massa e do teor de ar incorporado. Rio de Janeiro, 2005b.

ASSOCIAÇÃO BRASILEIRA DE NORMAS TÉCNICAS. NBR 13279: argamassa para assentamento e revestimento de paredes e tetos: determinação da resistência à tração na flexão e à compressão. Rio de Janeiro, 2005c.

ASSOCIAÇÃO BRASILEIRA DE NORMAS TÉCNICAS. NBR 13280: argamassa para assentamento e revestimento de paredes e tetos: determinação da densidade de massa aparente no estado endurecido. Rio de Janeiro, 2005d.

ASSOCIAÇÃO BRASILEIRA DE NORMAS TÉCNICAS. NBR 15630: argamassa para assentamento e revestimento de paredes e tetos: determinação do módulo de elasticidade dinâmico através da propagação de onda ultra-sônica. Rio de Janeiro, 2008.

ASSOCIAÇÃO BRASILEIRA DE NORMAS TÉCNICAS. NBR 15839: argamassa de assentamento e revestimento de paredes e tetos: caracterização reológica pelo método squeeze-flow. Rio de Janeiro, 2010.

ASSOCIAÇÃO BRASILEIRA DE NORMAS TÉCNICAS. NBR 7215: cimento Portland: determinação da resistência à compressão. Rio de Janeiro, 2019.

ASSOCIAÇÃO BRASILEIRA DE NORMAS TÉCNICAS. NBR NM 248: agregados: determinação da composição granulométrica. Rio de Janeiro, $2003 \mathrm{~b}$. 
ASSOCIAÇÃO BRASILEIRA DE NORMAS TÉCNICAS. NBR NM 46: agregados: determinação do material fino que passa através da peneira $75 \mu \mathrm{m}$ por lavagem. Rio de Janeiro, 2003a.

ASSOCIAÇÃO BRASILEIRA DE NORMAS TÉCNICAS. NBR NM 52: agregados: determinação da massa específica e massa específica aparente. Rio de Janeiro, 2009.

BAUER, B.; OLIVEIRA, V. C. Comportamentos e propriedades das argamassas estabilizadas de revestimento. In: SIMPÓSIO BRASILEIRO DE TECNOLOGIA DE ARGAMASSA, 10., São Paulo, 2017. Anais [...] São Paulo, 2017.

CAMPOS, G. M. Estudo do tempo de início de pega de argamassas com aditivo estabilizador de hidratação. Curitiba, 2012. 116 f. Monografia (Especialização em Patologia das Construções) Universidade Tecnológica Federal do Paraná, Curitiba, 2012.

CASALI, J. M. et al. Avaliação das propriedades do estado fresco e endurecido da argamassa estabilizada para revestimento. In: SIMPÓSIO BRASILEIRO DE TECNOLOGIA DE ARGAMASSA, 9., Belo Horizonte, 2011. Anais [...] Belo Horizonte, 2011.

CASALI, J. M. et al. Influence of cement type and water content on the fresh state properties of ready mix mortar. Ambiente Construído, Porto Alegre, v. 18, n. 2, p. 33-52, abr./jun. 2018.

CHEUNG, J. et al. Impact of admixtures on the hydration kinetics of Portland cement. Cement and concrete research, v. 41, n, 12, p 1289-1309, dec.2011.

FIORAVANTE, E. V. Influência dos aditivos nas propriedades de argamassas estabilizadas. Ponta Grossa, 2014. 64 f. Trabalho de Conclusão de Curso (Engenharia de Civil) - Universidade Estadual de Ponta Grossa, Ponta Grossa, 2014.

GONÇALVEZ, J. P.; TOLEDO FILHO, R. D.; FAIRBAIRN, E. M. R. Estudo da hidratação de pastas de cimento Portland contendo resíduo cerâmico por meio de análise térmica. Ambiente Construído, Porto Alegre, v. 6, n. 4, p. 83-94, out./dez. 2006.

GUINDANI, E. N. Argamassa estabilizada para revestimento: avaliação da influência da adição de finos nas propriedades do estado fresco endurecido. Florianópolis, 2018. 146 f. Dissertação (Mestre em Engenharia Civil) - Centro Tecnológico, Universidade Federal de Santa Catarina, Florianópolis, 2018.

HOPPE FILHO, J. Sistemas cimento, cinza volante e cal hidratada: mecanismo de hidratação, microestrutura e carbonatação de concreto. São Paulo, 2008. 247 f. Dissertação (Mestre em Engenharia Civil) - Escola Politécnica da Universidade de São Paulo, Universidade de São Paulo, São Paulo, 2008.

LAM, L.; WONG, Y.L.; POON, C.S. Degree of hydration and gel/space ratio of high volume fly ash/cement systems. Cement and Concrete Research, v. 30, p. 747-56, 2000.

LOTHENBACH, B.; DURDZINSKI, P.; WEERDT, K. Thermogravimetric analysis. In: SCRIVENER, K.; SNELLINGS, R.; LOTHENBACH, B. (ed.). A practical guide to microstructural analysis of cementitious materials. New York: Taylor \& Francis Group, 2016.

MACIOSKI, G. Avaliação do comportamento de argamassas estabilizadas para revestimento. Curitiba, 2014. 115 f. Trabalho de Conclusão de Curso (Engenharia de Civil) - Escola de Engenharia, Universidade Federal do Paraná, Curitiba, 2014.

MASUELA, F. B.; CAMARINI, G. Avaliação do grau de hidratação do cimento por perda ao fogo. In: ENCONTRO NACIONAL DE TECNOLOGIA DO AMBIENTE CONSTRUÍDO, 16., São Paulo, 2016. Anais [...] São Paulo, 2016.

MEES, S. et al. Avaliação do grau de hidratação ao longo do tempo de argamassas estabilizadas por perda ao fogo. In: ENCONTRO NACIONAL DE TECNOLOGIA DO AMBIENTE CONSTRUÍDO, 18., Foz do Iguaçu, 2018. Anais [...] Porto Alegre: ANTAC, 2018.

NARMLUK, M.; NAWA, T. Effect of fly ash on the kinetics of Portland cement hydration at different curing temperatures. Cement and Concrete Research, v. 41, p. 579-89, 2011.

NEVILLE, A. M. Propriedades do concreto. 2. ed. São Paulo: PINI, 1997.

PAOLINI, M.; KHURANA, R. Admixtures for recycling of waste concrete. Cement and concrete composites, v. 20, p. 221-229, 1998. 
PIVETTA, D. M. et al. Desempenho de argamassas estabilizadas: influência do aditivo estabilizador de hidratação no estado fresco. In: CONGRESSO BRASILEIRO DO CONCRETO, 58., Belo Horizonte, 2016. Anais [...] Belo Horizonte, 2016.

ROMANO, R. C. O. Incorporação de ar em materiais cimentícios aplicadas em construção civil. São Paulo, 2013. 200 f. Tese (Doutorado em Engenharia Civil) - Escola Politécnica, Universidade de São Paulo, São Paulo, 2013.

TAYLOR, H. F. W. Cement chemistry. 2. ed. London: Thomas Telford, 1997.

VIECILI, M. J. C.; HASTENPFLUG, D.; GIRARDI, R. Comparativo entre o teste de Vicat e a calorimetria semi-adiabática para determinação do tempo de início e fim de pega em cimentos Portland. Revista

Matéria, v. 23, n. 3, 2018.

\title{
Agradecimentos
}

Os autores agradecem ao Instituto Federal de Santa Catarina (IFSC) pela infraestrutura e financiamento pelo Edital Universal de Pesquisa n. 02/2017/PROPPI. Os autores também agradecem às empresas pela doação de agregado miúdo e dos aditivos.

Juliana Machado Casali

Departamento Acadêmico de Construção Civil | Instituto Federal de Santa Catarina | Av. Mauro Ramos, 950 | Florianópolis - SC - Brasil | CEP 88020-300 | Tel.: (48) 3211-6060 | E-mail: juliana.casali@ifsc.edu.br

\section{Sabrina Mees}

Departamento Acadêmico de Construção Civil | Instituto Federal de Santa Catarina | Tel.: (48) 99968-66244 | E-mail:

binamees@gmail.com

Alexandre Lima de Oliveira

Departamento Acadêmico de Construção Civil | Instituto Federal de Santa Catarina | Tel.: (48) 3211-6060 | E-mail: alexandre@ifsc.edu.br

Andrea Murillo Betioli

Departamento Acadêmico de Construção Civil | Instituto Federal de Santa Catarina | E-mail: andrea.betioli@ifsc.edu.br

Luciana Maltez Calçada

Departamento Acadêmico de Construção Civil | Instituto Federal de Santa Catarina | E-mail: lucianamaltez@ifsc.edu.br

\author{
Ambiente Construído \\ Revista da Associação Nacional de Tecnologia do Ambiente Construído \\ Av. Osvaldo Aranha, $99-3^{\circ}$ andar, Centro \\ Porto Alegre - RS - Brasil$$
\text { CEP } 90035-190
$$ \\ Telefone: +55 (51) 3308-4084 \\ Fax: +55 (51) 3308-4054 \\ www.seer.ufrgs.br/ambienteconstruido \\ E-mail: ambienteconstruido@ufrgs.br
}

